\title{
Iodonium salts in organic synthesis
}

\author{
Mekhman S. Yusubov, ${ }^{\mathrm{a}}$ Andrey V. Maskaev, ${ }^{\mathrm{b}}$ and Viktor V. Zhdankin*,b \\ ${ }^{a}$ The Siberian State Medical University and The Tomsk Polytechnic University, \\ 634050 Tomsk, Russia \\ ${ }^{b}$ Department of Chemistry and Biochemistry, University of Minnesota Duluth, \\ Duluth, Minnesota, 55812, USA \\ E-mail:vzhdanki@d.umn.edu
}

\begin{abstract}
This review summarizes the chemistry of iodonium salts with emphasis of their synthetic applications. The preparation and reactions of diaryliodonium, alkenyl(aryl)iodonium, alkynyl(aryl)iodonium, and alkyl(aryl)iodonium salts are overviewed. Application of these reagents allows mild and highly selective arylations, alkenylations, alkynylations, and alkylations of various organic and inorganic substrates in a facile and environmentally friendly manner.
\end{abstract}

Keywords: Hypervalent iodine, diaryliodonium, alkenyl(aryl)iodonium, alkynyl(aryl)iodonium, alkyl(aryl)iodonium salts

\section{Contents}

1. Introduction

2. Classification and General Structural Features of Iodonium Salts

3. Preparation of Iodonium Salts

3.1. Diaryliodonium salts

3.2. Alkenyl(aryl)iodonium salts

3.3. Alkynyl(aryl)iodonium salts

3.4. Alkyl(aryl)iodonium salts

4. Applications of Iodonium Salts

4.1. Arylations

4.2. Alkenylations

4.3. Reactions of alkynyl(aryl)iodonium salts

4.4. Alkylations and fluoroalkylations

4.5. Introduction of fluorine and application in PET 
5. Conclusions and Outlook

6. Acknowledgements

7. References

\section{Introduction}

Since the beginning of the 21 st century, the organic chemistry of hypervalent iodine compounds has experienced an unprecedented, explosive development. Now hypervalent iodine compounds are widely used in organic synthesis as efficient reagents whose chemical properties are similar to transition metals derivatives, like mercury(II), thallium(III), lead(IV), osmium(VIII) and chromium(VI), but without the toxicity and environmental problems associated with these heavy metals. Many reviews, some comprehensive, but most dealing with specific aspects of hypervalent organoiodine chemistry, have been published just in the last ten years. ${ }^{1}$ Particularly noteworthy was the publication of commemorative issue of Arkivoc honoring Prof. Anastasios Varvoglis, in which 22 research articles and accounts covered all key areas of hypervalent iodine chemistry. ${ }^{2}$ More recently, a Symposium-in-Print Tetrahedron issue dedicated to recent advances and applications of hypervalent iodine chemistry in concert with the third International Conference on Hypervalent Iodine Chemistry (ICHCI2010) has been compiled by Quideau and Wirth. ${ }^{3}$ Previously we have published two review in Arkivoc summarizing synthetic applications of hypervalent iodine $(\mathrm{V})^{4 \mathrm{a}}$ and hypervalent iodine(III $)^{4 \mathrm{~b}}$ compounds. The purpose of the present review is to summarize the chemistry of iodonium salts, $\mathrm{R}_{2} \mathrm{I}^{+} \mathrm{X}^{-}$, with emphasis on recent synthetic applications, the literature coverage is through May 2011. To our knowledge, this is the first comprehensive review covering the chemistry of all classes of iodonium salts. Several earlier reviews have discussed more specific aspects of the chemistry of alkynyliodoniun salts, ${ }^{5 a}$ alkenyliodonium salts, ${ }^{5 \mathrm{~b}-\mathrm{d}}$ diaryliodonium salts, ${ }^{5 \mathrm{e}, \mathrm{f}}$ and fluoroalkyliodonium salts. ${ }^{5 \mathrm{~g}}$

\section{Classification and General Features of Iodonium Salts}

Hypervalent iodine organic compounds belong to two general structural types: (1) iodine(III) compounds 1 and 2, also named $\lambda^{3}$-iodanes according to IUPAC recommendations, and (2) iodine(V) compounds $\mathbf{3}$, or $\lambda^{5}$-iodanes (Scheme 1). The iodine atom in $\lambda^{3}$-iodanes $\mathbf{1}$ has a total 10 electrons and the overall geometry of a distorted trigonal bipyramid with two heteroatom ligands L occupying the axial positions, and the least electronegative aryl group and both electron pairs residing in equatorial positions. Iodonium salts $\mathbf{2}$, with consideration of the closely associated anionic part of the molecule, have similar pseudo trigonal bipyramidal geometry and are generally classified as hypervalent $\lambda^{3}$-iodanes with two carbon ligands $\left(\mathrm{R}_{2} \mathrm{IX}, 2\right)$. In the hypervalent model, bonding in $\mathrm{RIX}_{2}$ uses the non-hybridized 5p orbital of iodine in the linear X$\mathrm{I}-\mathrm{X}$ bond. Such a linear three-center, four-electron $(3 \mathrm{c}-4 \mathrm{e})$ bond is highly polarized and is longer 
and weaker compared to a regular covalent bond. This bond is termed "hypervalent" and the presence of this bond in $\lambda^{3}$-iodanes is responsible for their high electrophilic reactivity.

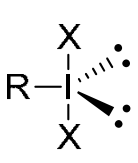

1

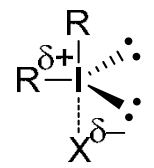

2

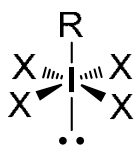

3

$\mathrm{R}=$ carbon ligand; $\mathrm{X}=$ halogen-, $\mathrm{O}-$, or $\mathrm{N}$-ligand

Scheme 1. Common classes of hypervalent iodine compounds.

X-ray structural data for the overwhelming majority of iodonium salts $\mathrm{R}_{2} \mathrm{IX} \mathbf{2}$ show that they have structure similar to $\lambda^{3}$-iodanes 1 . Their structure has trigonal bipyramidal geometry and experimentally determined bond angle $\mathrm{R}-\mathrm{I}-\mathrm{R}$ is close to $90^{\circ}$. X-ray data also shows the presence of significant secondary bonding between the iodine atom and the anion $\mathrm{X}$ with average bond distances within a range of 2.3 to $2.7 \AA$.

Diaryliodonium salts were discovered more than a hundred years ago and they are most investigated among iodonium salts. Their chemistry was extensively covered in previous reviews, most notably, in a recent review of Merritt and Olofsson. ${ }^{5 e}$ Since the 1980 s significant research activity has been focused on aryliodonium derivatives, $\operatorname{Ar}(\mathrm{R}) \mathrm{IX}$, containing alkynyl-, alkenyl-, or fluoroalkyl groups as ligand $\mathrm{R}$. These derivatives have found application as excellent reagents for the ligand $\mathrm{R}$ electrophilic transfer to electron-rich organic compounds. The high reactivity of aryliodonium salts, $\operatorname{Ar}(\mathrm{R}) \mathrm{IX}$, in these reactions is explained by the "hyperleaving group ability" of the ArI group. For example, the leaving group ability of $\mathrm{PhI}$ is about $10^{6}$ times greater than the triflate. ${ }^{6}$

Stable iodonium salts have found numerous practical applications, such as cationic photoinitiators in polymer chemistry, ${ }^{7}$ and as biologically active compounds. A summary of the biological properties of iodonium salts is provided in our 1996 review. $^{8}$ In a specific example, a study of the in vitro activities of several iodonium salts against oral and dental anaerobes has demonstrated that their activities are comparable to that of chlorhexidine and these compounds may be suitable for incorporation into an oral mouthwash. ${ }^{9}$

\section{Preparation of Iodonium Salts}

\subsection{Diaryliodonium salts}

Older methods for the preparation of diaryliodonium salts are based on the reaction of arenes with iodine and potassium iodate in the presence of concentrated sulfuric acid. ${ }^{10 a}$ Diaryliodonium tetrafluoroborates 5 and 7 can be conveniently prepared by the boron-iodine(III) exchange reaction of (diacetoxyiodo)arenes with tetraarylborates $4^{10 \mathrm{~b}}$ or arylboronic acids $\mathbf{6}^{10 \mathrm{c}, \mathrm{d}}$ followed by the treatment with a saturated sodium tetrafluoroborate solution (Scheme 2). Recent 
modification of this procedure involves using aryltrifluoroborates, $\mathrm{ArBF}_{3} \mathrm{~K}^{+}$, instead of tetraarylborates under mild conditions. ${ }^{11 \mathrm{a}}$ Likewise, fluoroorganoiodonium tetrafluoroborates $\left(\mathrm{C}_{6} \mathrm{~F}_{5}\right)_{2} \mathrm{I}^{+} \mathrm{BF}_{4}{ }^{-},\left(4-\mathrm{C}_{5} \mathrm{~F}_{4} \mathrm{~N}\right)_{2} \mathrm{I}^{+} \mathrm{BF}_{4}{ }^{-}$and $\left[\mathrm{C}_{6} \mathrm{~F}_{5}\left(4-\mathrm{C}_{5} \mathrm{~F}_{4} \mathrm{~N}\right) \mathrm{I}^{+} \mathrm{BF}_{4}{ }^{-}\right.$can be prepared by interaction of the appropriate (difluoroiodo)arenes with fluorinated organodifluoroboranes, $\mathrm{Ar}_{\mathrm{f}} \mathrm{BF}_{2}$, in dichloromethane at 0 to $20{ }^{\circ} \mathrm{C} .{ }^{11 \mathrm{~b}}$

$$
\begin{aligned}
& \text { 1. } \mathrm{AcOH}, \mathrm{rt} \\
& \begin{array}{cccc}
\operatorname{Arl}(\mathrm{OAc})_{2}+\left(4-\mathrm{MeOC}_{6} \mathrm{H}_{4}\right)_{4} \mathrm{~B}^{-} \mathrm{Na}^{+} & \stackrel{2 . \mathrm{NaBF}_{4}, \mathrm{H}_{2} \mathrm{O}}{\stackrel{49-63 \%}{\longrightarrow}} & 4-\mathrm{MeOC}_{6} \mathrm{H}_{4} \mathrm{I}^{+} \mathrm{Ar}-{ }^{-} \mathrm{BF}_{4} \\
\mathrm{Ar}=\mathrm{Ph} \text {, Tol } & \mathbf{4} & & \mathbf{5}
\end{array} \\
& \text { 1. } \mathrm{BF}_{3} \bullet \mathrm{Et}_{2} \mathrm{O}, \mathrm{CH}_{2} \mathrm{Cl}_{2} \\
& \mathrm{Phl}(\mathrm{OAC})_{2}+\underset{6}{\mathrm{ArB}(\mathrm{OH})_{2}} \stackrel{2 . \mathrm{NaBF}_{4}, \mathrm{H}_{2} \mathrm{O}}{73-83 \%} \underset{7}{\mathrm{Phl}}{ }^{+} \mathrm{Ar}^{-}{ }^{-} \mathrm{BF}_{4} \\
& \mathrm{Ar}=\mathrm{Ph}, 4-\mathrm{FC}_{6} \mathrm{H}_{4}, 4-\mathrm{ClC}_{6} \mathrm{H}_{4}, 4-\mathrm{MeOC}_{6} \mathrm{H}_{4} \text {, Tol }
\end{aligned}
$$

\section{Scheme 2}

Another protocol uses a similar tin-iodine(III) and silicon-iodine(III) exchange reaction of (diacetoxyiodo)arenes or iodosylbenzene with tetraphenylstannane or trimethylsilylbenzene in the presence of boron trifluoride etherate. ${ }^{12}$

Frohn and co-workers reported the preparation of a perfluoroaryliodonium salt, $\left(\mathrm{C}_{6} \mathrm{~F}_{5}\right)_{2} \mathrm{I}^{+}$ $\mathrm{AsF}_{6}^{-}$, by the electrophilic arylation of $\mathrm{C}_{6} \mathrm{~F}_{5} \mathrm{I}$ with a stable pentafluorophenylxenonium hexafluoroarsenate, $\mathrm{C}_{6} \mathrm{~F}_{5} \mathrm{Xe}^{+} \mathrm{AsF}_{6}{ }^{-13}$

Numerous methods for the preparation of symmetrical and unsymmetrical diaryl- and hetaryliodonium sulfates and organosulfonates have been reported. Usually unsymmetrical diaryl- and hetaryl(aryl)iodonium tosylates are obtained by reactions of [hydroxy(tosyloxy)iodo]arenes with arenes, ${ }^{14 \mathrm{a}}$ aryl- or hetaryltrimethylsilanes, ${ }^{14 \mathrm{~b}, \mathrm{c}}$ aryltributylstannanes, ${ }^{14 \mathrm{~d}-\mathrm{f}}$ or arylboronic acids. ${ }^{14 \mathrm{~g}}$ The reaction of [hydroxy(tosyloxy)iodo]benzene with arylstannanes proceeds under milder conditions compared to arylsilanes and is applicable to a wide range of arenes with electron-withdrawing substituents. Arylboronic acids in general have some advantage over arylstannanes in the case of the electron-rich heterocyclic precursors. ${ }^{14 \mathrm{~g}}$

A common procedure for obtaining unsymmetrically functionalized diaryliodonium triflates 10 from iodosylbenzene ${ }^{15 \mathrm{a}}$ or (diacetoxyiodo)arenes $\mathbf{8}^{15 \mathrm{~b}}$ in reaction with arenes 9 in trifluoromethanesulfonic acid is shown in Scheme 3. This procedure is simple and provides diaryliodonium triflates in relatively high yields, but it is limited to aromatic substrates that are not sensitive to strong acids. Moreover, the formation of the $p$-phenylene type oligomeric iodonium salts as side products may occur upon the reaction of (diacetoxyiodo)benzene with trifluoromethanesulfonic acid. ${ }^{15 \mathrm{c}}$ This procedure was improved to carry out the reaction more selective and under milder conditions, obtaining desired aryl(phenyl)iodonium triflates from 
(diacetoxyiodo)benzene and arylboronic acids in the presence of triflic acid at $-30{ }^{\circ} \mathrm{C}$ in $74-97 \%$ yields. $^{14 \mathrm{~g}}$

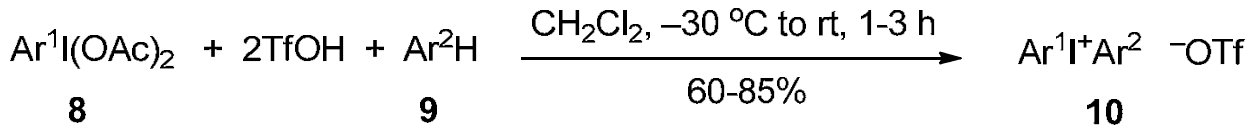

$$
\begin{aligned}
& \mathrm{Ar}^{1}=\mathrm{Ph}, 2-\mathrm{MeC}_{6} \mathrm{H}_{4}, 3-\mathrm{MeC}_{6} \mathrm{H}_{4}, 3,5-\mathrm{Me}_{2} \mathrm{C}_{6} \mathrm{H}_{3}, 2,4,6-\mathrm{Me}_{3} \mathrm{C}_{6} \mathrm{H}_{2}, 3-\mathrm{MeOC}_{6} \mathrm{H}_{4} \\
& \mathrm{Ar}^{2}=4-\mathrm{MeC}_{6} \mathrm{H}_{4}, 4-\mathrm{MeOC}_{6} \mathrm{H}_{4}, 2,4,6-\mathrm{Me}_{3} \mathrm{C}_{6} \mathrm{H}_{2}, 4-\mathrm{Bu}^{\mathrm{t}} \mathrm{CH}_{2} \mathrm{C}_{6} \mathrm{H}_{4}
\end{aligned}
$$

\section{Scheme 3}

Several modified procedures for the preparation of diaryliodonium triflates have recently been reported. ${ }^{16}$ Kitamura and Hossain have developed a one-pot reaction to obtain symmetrical diaryliodonium triflates in good yields directly from iodoarenes and aromatic substrates using $\mathrm{K}_{2} \mathrm{~S}_{2} \mathrm{O}_{8}$ as an oxidant. ${ }^{16 a}$ Additional improvements of this procedure consist of the reaction of arenes with elemental iodine and $\mathrm{K}_{2} \mathrm{~S}_{2} \mathrm{O}_{8}$ in trifluoroacetic acid, followed by treatment with sodium triflate (Scheme 4). ${ }^{16 b, c}$

1. $\mathrm{K}_{2} \mathrm{~S}_{2} \mathrm{O}_{8}, \mathrm{CF}_{3} \mathrm{CO}_{2} \mathrm{H}, 40^{\circ} \mathrm{C}, 72 \mathrm{~h}$

$$
\begin{aligned}
& \mathrm{ArH}+\mathrm{I}_{2} \underset{11-69 \%}{\stackrel{\text { 2. aq. NaOTf, } \mathrm{rt}, 12 \mathrm{~h}}{\longrightarrow}} \mathrm{Ar}_{2} \mathrm{I}^{+}{ }^{-} \mathrm{OTf} \\
& \mathrm{Ar}=4-\mathrm{FC}_{6} \mathrm{H}_{4}, 4-\mathrm{ClC}_{6} \mathrm{H}_{4}, 4-\mathrm{BrC}_{6} \mathrm{H}_{4}, 4-\mathrm{IC}_{6} \mathrm{H}_{4}, 4-\mathrm{MeC}_{6} \mathrm{H}_{4}, 4-\mathrm{Bu}^{\mathrm{t}} \mathrm{C}_{6} \mathrm{H}_{4}
\end{aligned}
$$

\section{Scheme 4}

Olofsson and co-workers have developed several efficient one-pot syntheses of diaryliodonium salts. ${ }^{16 \mathrm{~d}-\mathrm{i}}$ A general and universal procedure provides both symmetrical and unsymmetrical diaryliodonium triflates $\mathbf{1 3}$ from both electron-deficient and electron-rich arenes 12 and aryl iodides 11 using mCPBA as the oxidant and triflic acid (Scheme 5). ${ }^{16 \mathrm{~d}-\mathrm{f}}$ The electronrich diaryliodonium tosylates are prepared similarly using toluenesulfonic acid instead of triflic acid as the additive. ${ }^{16 \mathrm{f}}$ Symmetrical diaryliodonium triflates can be synthesized by a modified one-pot procedure from iodine, arenes, $m \mathrm{CPBA}$ and triflic acid under similar conditions. ${ }^{16 \mathrm{~d}, \mathrm{e}} \mathrm{A}$ similar procedure based on a one-pot reaction of arylboronic acids, aryl iodides, $m \mathrm{CPBA}$ and $\mathrm{BF}_{3} \cdot \mathrm{Et}_{2} \mathrm{O}$ has recently been used for regioselective synthesis of unsymmetrical diaryliodonium tetrafluoroborates. ${ }^{16 \mathrm{~g}, \mathrm{~h}}$ In a further improvement of this approach, a range of symmetrical and unsymmetrical diaryliodonium triflates were prepared employing urea- $\mathrm{H}_{2} \mathrm{O}_{2}$ as the environmentally benign oxidizing agent. ${ }^{16 \mathrm{i}} \mathrm{Kita}$ and co-workers have recently demonstrated that 
hexafluoroisopropanol (HFIP) can be used as a highly efficient solvent for the synthesis of various diaryliodonium salts. ${ }^{16 \mathrm{j}, \mathrm{k}}$

Skulski and Kraszkiewicz have also reported a new direct method for the preparation of various symmetrical diaryliodonium bromides (in 15-88\% crude yields) from arenes by the reaction of $\mathrm{ArH}$ with $\mathrm{NaIO}_{4}$ in sulfuric acid followed by the addition of $\mathrm{KBr} .{ }^{17}$

$$
\begin{aligned}
& \text { mCPBA, TfOH, } \mathrm{CH}_{2} \mathrm{Cl}_{2} \\
& A r^{1} \mathrm{I}+\mathrm{Ar}^{2} \mathrm{H} \quad \stackrel{\mathrm{rt} \text { to } 80^{\circ} \mathrm{C}, 1-21 \mathrm{~h}}{\mathrm{Ar}} \mathrm{Ar}^{1} \mathrm{I}^{+} \mathrm{Ar}{ }^{2}-\mathrm{OTf} \\
& 11 \quad 12 \quad 51-91 \% \quad 13 \\
& \mathrm{Ar}^{1}=\mathrm{Ph}, 4-\mathrm{ClC}_{6} \mathrm{H}_{4}, 4-\mathrm{BrC}_{6} \mathrm{H}_{4}, 2-\mathrm{MeC}_{6} \mathrm{H}_{4}, 4-\mathrm{MeC}_{6} \mathrm{H}_{4}, 4-\mathrm{Bu}^{\mathrm{t}} \mathrm{C}_{6} \mathrm{H}_{4}, 4-\mathrm{NO}_{2} \mathrm{C}_{6} \mathrm{H}_{4} \text {, } \\
& \text { 4- } \mathrm{CF}_{3} \mathrm{C}_{6} \mathrm{H}_{4}, 4-\mathrm{HO}_{2} \mathrm{CC}_{6} \mathrm{H}_{4}, 3-\mathrm{CF}_{3} \mathrm{C}_{6} \mathrm{H}_{4} \text {, 2-chloro-5-pyridinyl } \\
& \mathrm{Ar}^{2}=\mathrm{Ph}, 4-\mathrm{ClC}_{6} \mathrm{H}_{4}, 4-\mathrm{BrC}_{6} \mathrm{H}_{4}, 4-\mathrm{FC}_{6} \mathrm{H}_{4}, 4-\mathrm{MeOC}_{6} \mathrm{H}_{4}, 4-\mathrm{Bu}^{\mathrm{t}} \mathrm{C}_{6} \mathrm{H}_{4}, 4-\mathrm{MeC}_{6} \mathrm{H}_{4} \text {, } \\
& \text { 2,4,6- }-\mathrm{Me}_{3} \mathrm{C}_{6} \mathrm{H}_{2}, 2,5-\mathrm{Me}_{2} \mathrm{C}_{6} \mathrm{H}_{3}, 2,5-\mathrm{Bu}_{2}^{\mathrm{t}} \mathrm{C}_{6} \mathrm{H}_{3}
\end{aligned}
$$

\section{Scheme 5}

A very mild and general method for the preparation of diaryl- and heteroaryliodonium triflates is based on iodonium transfer reactions of iodine(III) cyanides with the respective arylor heteroarylstannanes. ${ }^{18}$ Specifically, (dicyano)iodonium triflate 14, generated in situ from iodosyl triflate and TMSCN, reacts with tributyltin derivatives of aromatic and heteroaromatic compounds affording the corresponding symmetrical iodonium salts under very mild conditions (Scheme 6). ${ }^{18 c, d}$

$$
\begin{aligned}
& \left(\mathrm{NC}_{2} \mathrm{I}^{+}-\mathrm{OTf}+2 \mathrm{ArSnBu}_{3} \frac{\mathrm{CH}_{2} \mathrm{Cl}_{2},-40 \text { to } 20^{\circ} \mathrm{C}}{41-75 \%} \mathrm{Ar}_{2} \mathrm{I}^{+}-\mathrm{OTf}\right. \\
& \quad \begin{array}{l}
14 \\
\mathrm{Ar}=\mathrm{Ph}, 3-\mathrm{MeOC}_{6} \mathrm{H}_{4}, 4-\mathrm{MeOC}_{6} \mathrm{H}_{4}, \text { 2-furyl, 2-thienyl, 4-pyrazolyl, etc. }
\end{array}
\end{aligned}
$$

\section{Scheme 6}

Similar iodonium exchange reaction involves aryl(cyano)iodonium triflates $\mathbf{1 5}$ and stannylated aromatic precursors providing many kinds of diaryl or aryl(heteroaryl) iodonium salts. ${ }^{18 a, b, e}$ Tykwinski, Hinkle and co-workers have reported an application of such iodonium transfer reaction for obtaining of a series of mono- and bithienyl(aryl)iodonium triflates 16 with increasingly electron-withdrawing substituents on the aryl moiety (Scheme 7). ${ }^{18 \mathrm{e}}$ 


$$
\begin{aligned}
& \mathrm{Arl}^{+} \mathrm{CN}-\mathrm{OTf}+{ }_{15} \\
& \mathrm{Ar}=\mathrm{Ph}, \mathrm{n}=1 ; \mathrm{Ar}=\mathrm{Ph}, \mathrm{n}=2 \\
& \mathrm{Ar}=4-\mathrm{CF}_{3} \mathrm{C}_{6} \mathrm{H}_{4}, \mathrm{n}=2 ; \mathrm{Ar}=3-\mathrm{ClC}_{6} \mathrm{H}_{4}, \mathrm{n}=2
\end{aligned}
$$

\section{Scheme 7}

The preparation of several macrocyclic iodonium triflates, such as rhomboids 19, a square 22, and a pentagon 23 has been reported (Scheme 8). ${ }^{19}$ The rhomboid shaped molecules 19 were prepared by the treatment of compounds $\mathbf{1 7}$ and $\mathbf{1 8}$ with trimethylsilyl triflate. ${ }^{19 a}$ The reaction of 
<smiles>CC(C)(c1ccc(I([O-])O)cc1)c1ccc(I(O)O[AsH2])cc1</smiles><smiles>[R]C([R])(c1ccc([SiH2]C)cc1)c1ccc([SiH3]C(C)(C)C)cc1</smiles>

$18 \mathrm{R}=$ Me or $\mathrm{H}$
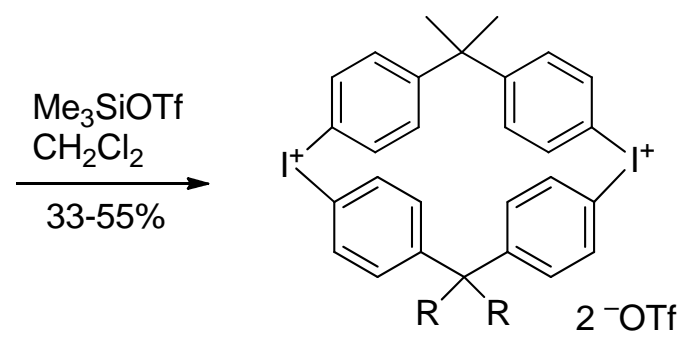

19
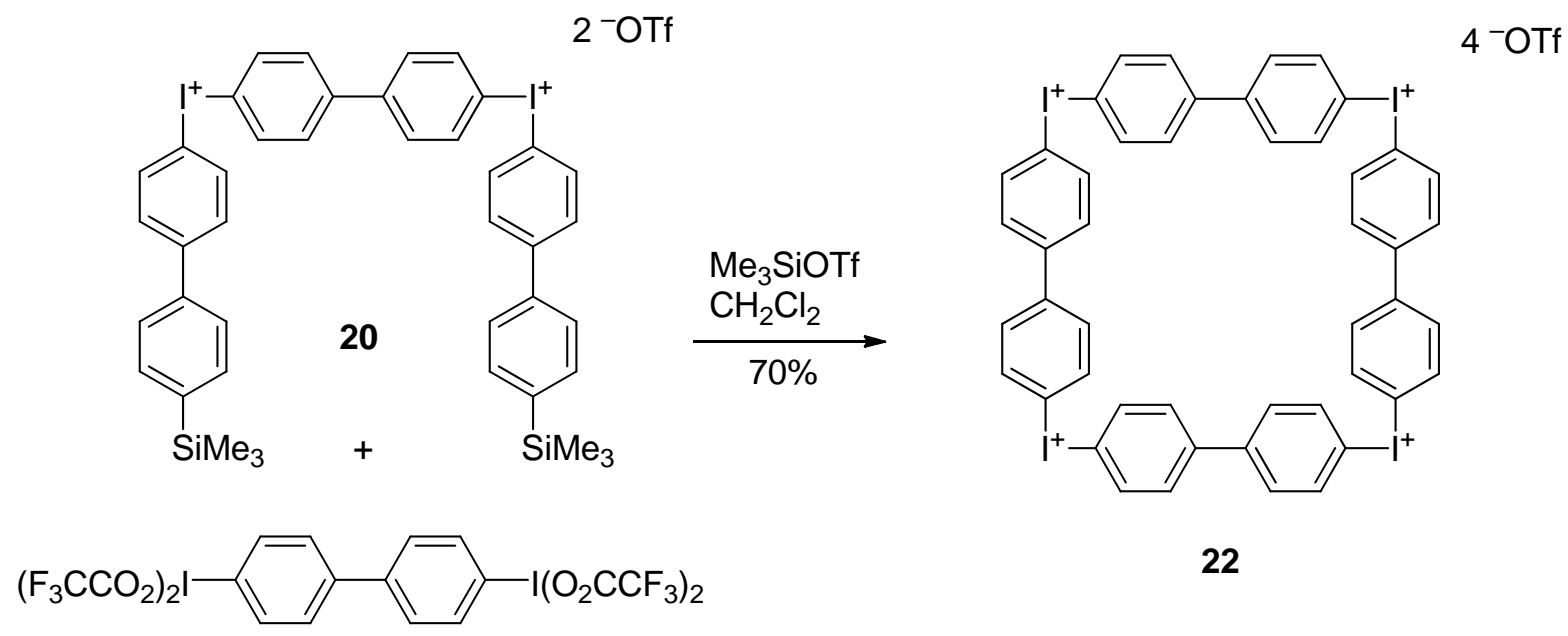

22

21
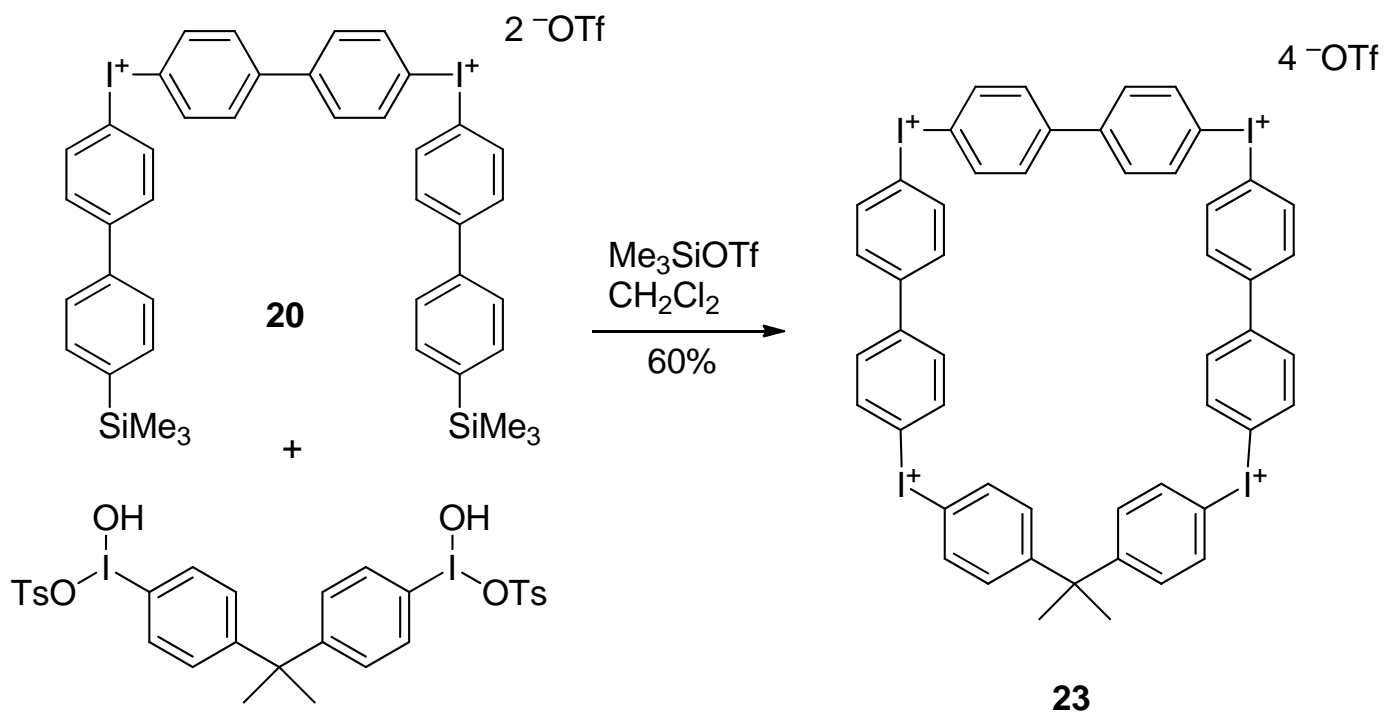

17

\section{Scheme 8}


dication 20 with compound 21 in the presence of $\mathrm{Me}_{3} \mathrm{SiOTf}$ gave an iodonium containing molecular square 22 in $70 \%$ yield. ${ }^{19}$ In addition, a pentagon-shaped macrocycle $\mathbf{2 3}$ was prepared in $60 \%$ yield from precursors $\mathbf{2 0}$ and $\mathbf{1 7}$. The structures of these iodonium-containing charged macrocycles were established using elemental analysis, multinuclear NMR and mass spectrometry. These iodonium-containing macromolecules may find potential application in nanotechnology. ${ }^{19 a}$

A very mild and selective approach to aryl- and hetaryliodonium chlorides $\mathbf{2 6}$ is based on the reaction of the appropriate aryllithium $\mathbf{2 4}$ (generated in situ from bromoarenes and butyllithium) with trans-(chlorovinyl)iodonium dichloride 25 (Scheme 9) ${ }^{20}$ The iodonium transfer reagent 25 is prepared by the reaction of iodine trichloride with acetylene in concentrated hydrochloric acid ${ }^{20 c}$ this compound is extremely unstable and should be handled and stored with proper safety precautions. ${ }^{20 \mathrm{~b}}$ The iodonium transfer procedure with reagent $\mathbf{2 5}$ is particularly useful for the preparation of bis(hetaryl)iodonium chlorides $\mathbf{2 8}$ from the appropriate nitrogen heterocycles $\mathbf{2 7}$ (Scheme 9). ${ }^{20 \mathrm{~b}}$

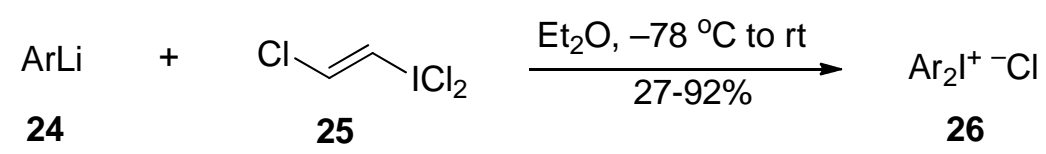

$\mathrm{Ar}=\mathrm{Ph}, \mathrm{Tol}$, 1-naphthyl, 2-naphthyl, 2-thienyl, 2-furanyl, etc.

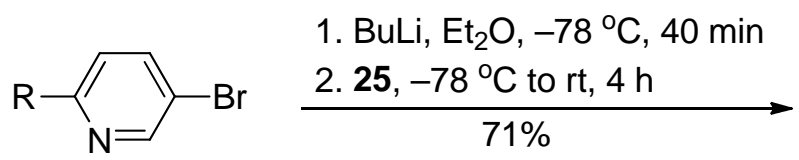

$27 \mathrm{R}=\mathrm{H}$ or $\mathrm{Cl}$

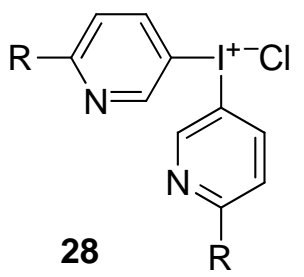

\section{Scheme 9}

\subsection{Alkenyl(aryl)iodonium salts}

Boron trifluoride-catalyzed silicon-iodine(III) exchange reaction of organosilanes 29 with iodosylarenes followed by treatment with aqueous $\mathrm{NaBF}_{4}$ constitutes the most general method for synthesis of alkenyl(aryl)iodonium tetrafluoroborates 30 (Scheme 10). ${ }^{10 b, 21}$ This reaction proceeds under mild conditions and in a stereospecific manner with retention of geometry of organosilanes. 


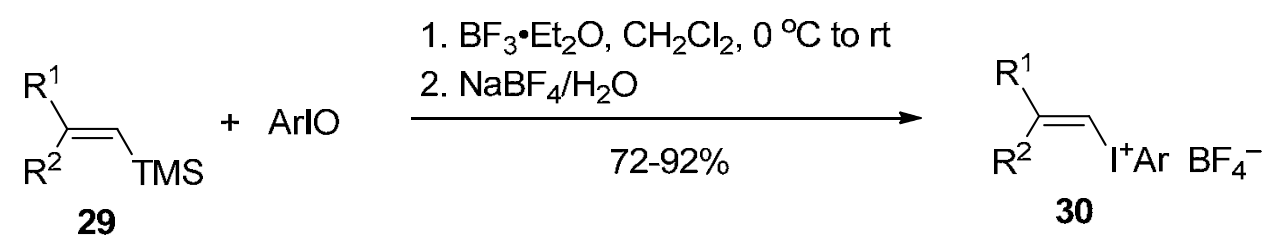

$\mathrm{R}^{1}=4-\mathrm{BrC}_{6} \mathrm{H}_{4} \mathrm{OCH}_{2}, \mathrm{PhCH}_{2} \mathrm{CH}_{2}, 4-\mathrm{ClC}_{6} \mathrm{H}_{4} \mathrm{OCH}_{2}, \mathrm{n}-\mathrm{C}_{8} \mathrm{H}_{17}$, etc.

$\mathrm{R}^{2}=\mathrm{H}, \mathrm{Me} ; \mathrm{Ar}=\mathrm{Ph}, 2,4,6-\mathrm{Me}_{3} \mathrm{C}_{6} \mathrm{H}_{2}$, etc.

\section{Scheme 10}

A similar borane-iodine(III) exchange of organoboronic acids 31 with iodosylbenzene or (diacetoxyiodo)benzene in the presence of boron trifluoride etherate is an efficient alternative method for a selective preparation of alkenyl(phenyl)iodonium tetrafluoroborates $\mathbf{3 2}$ in excellent yields (Scheme 11). ${ }^{22}$

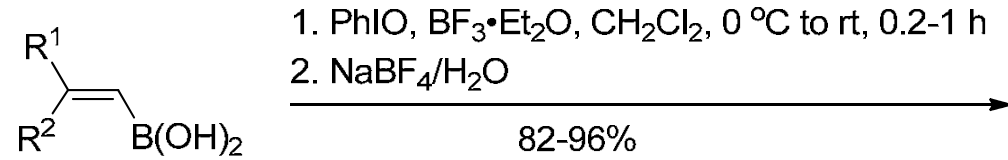

31

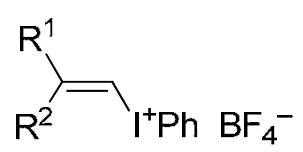

32

$$
\mathrm{R}^{1}=\mathrm{Bu}, \mathrm{Bu}{ }^{\mathrm{t}}, \mathrm{Ph}\left(\mathrm{CH}_{2}\right)_{3},\left(\mathrm{CH}_{3}\right)_{2} \mathrm{CH}\left(\mathrm{CH}_{2}\right)_{2} \text {, etc.; } \mathrm{R}^{2}=\mathrm{H}, \mathrm{Me}
$$

\section{Scheme 11}

(E)- $\beta$-Fluoroalkenyl(tolyl)iodonium tetrafluoroborates $\mathbf{3 3}$ are conveniently synthesized by the treatment of terminal alkynes with 4-iodotoluene difluoride in the presence of boron trifluoride etherate (Scheme 12). ${ }^{23 a}$ This reaction occurred instantaneously at $-78{ }^{\circ} \mathrm{C}$ to give fluoroalkenyliodonium salts $\mathbf{3 3}$ in good yields with high stereoselectivity. Likewise, various alkenyliodonium organosulfonates can be synthesized via electrophilic addition of the appropriate hypervalent iodine reagents to alkynes. ${ }^{23 \mathrm{~b}-\mathrm{d}}$

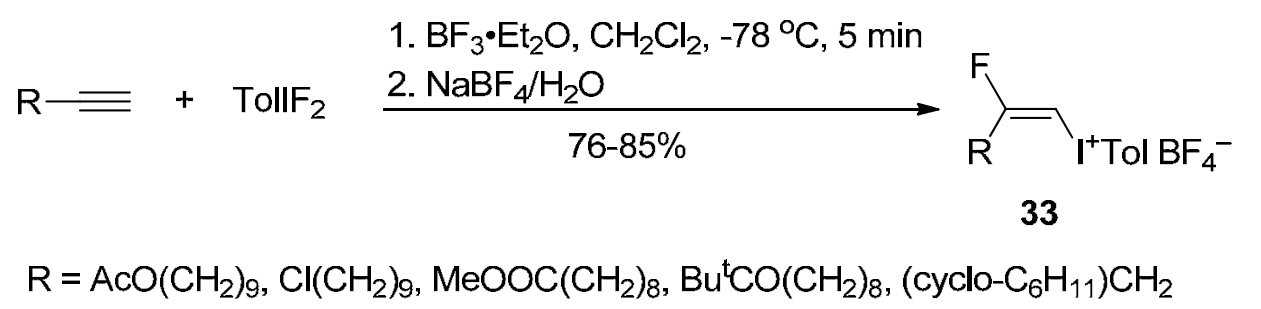

\section{Scheme 12}


(E)- $\beta$-Fluoroalkenyl(phenyl)iodonium tetrafluoroborates 35 can be stereoselectively prepared by the reaction of alkynyl(phenyl)iodonium salts $\mathbf{3 4}$ with aqueous HF in good yields (Scheme 13). ${ }^{24}$ The method is applicable to the synthesis of fluoroalkenyliodonium salts having functional groups such as ketone, ester, and chloride.

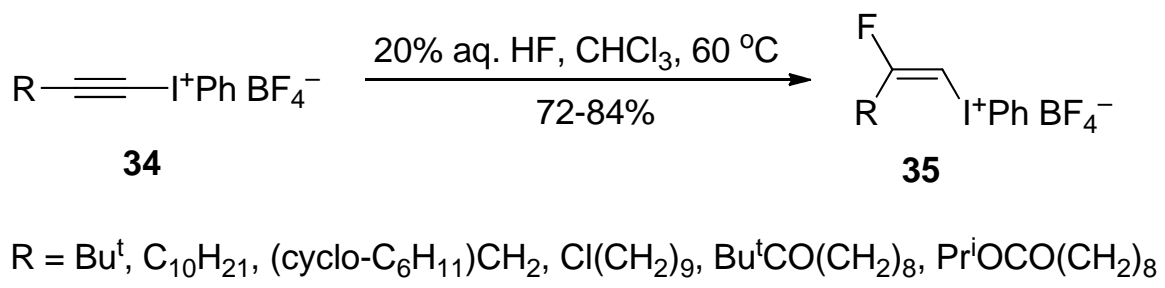

\section{Scheme 13}

A very general and mild procedure for the stereospecific synthesis of alkenyliodonium organosulfonates $\mathbf{3 8}$ involves the reaction of aryl(cyano)iodonium triflates and tosylates $\mathbf{3 7}$ with stannylated alkenes 36 (Scheme 14). ${ }^{25}$

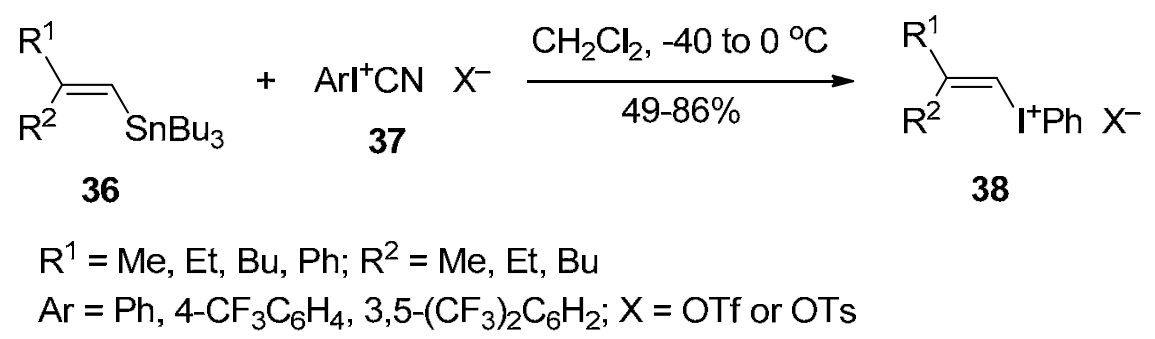

\section{Scheme 14}

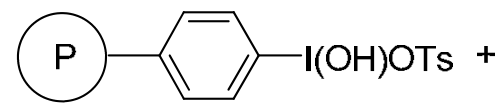

39<smiles>[R]N/C(C)=C\C(=O)O[R4]</smiles>

40

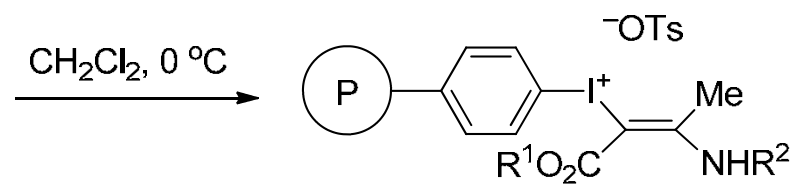

$\mathrm{R}^{1}=\mathrm{H}, \mathrm{Bn} ; \mathrm{R}^{2}=\mathrm{Me}, \mathrm{Et}$

41

\section{Scheme 15}

The polymer-supported alkenyliodonium tosylates 41 can be prepared by the treatment of polystyrene-based resin 39 with 3 -aminocrotonate esters 40 (Scheme 15). ${ }^{26 a}$ The similar 
monomeric $\alpha$-acyl- $\beta$-aminoalkenyl(phenyl)iodonium tosylates have been synthesized by the reaction of amino substituted $\alpha, \beta$-unsaturated ketones with [hydroxy(tosyloxy)iodo]benzene. ${ }^{26 \mathrm{~b}}$

\subsection{Alkynyl(aryl)iodonium salts}

A widely used method for obtaining the alkynyl(phenyl)iodonium tetrafluoroborates involves the reaction of iodosylbenzene with alkynylsilanes and boron trifluoride etherate followed by treatment with aqueous $\mathrm{NaBF}_{4}{ }^{27 a, b}$ Varvoglis, Koumbis and co-workers have used this procedure for the preparation of several ortho-substituted arylethynyl(phenyl)iodonium tetrafluoroborates 43 from alkynylsilanes 42 (Scheme 16). ${ }^{27 \mathrm{c}}$

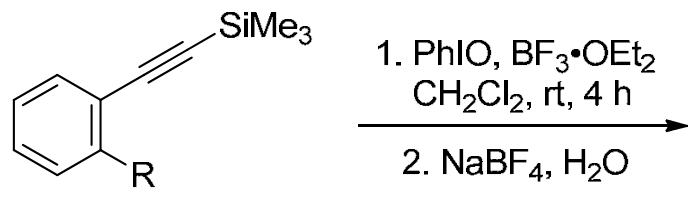

$42 \mathrm{R}=\mathrm{Me}, \mathrm{Et}, \mathrm{CH}_{2} \mathrm{OMe}$

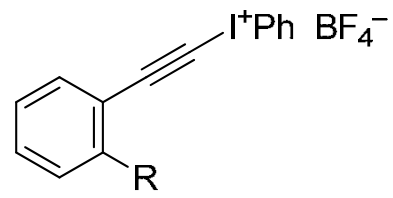

43

\section{Scheme 16}

A modified procedure for the synthesis of alkynyl(phenyl)iodonium tetrafluoroborates $\mathbf{4 5}$ reported by Hara and co-workers consists of the direct reaction of terminal alkynes 44 with iodosylbenzene, $42 \%$ aqueous solution of tetrafluoroboric acid, and a catalytic amount of mercury oxide (Scheme 17). ${ }^{27 \mathrm{~d}}$

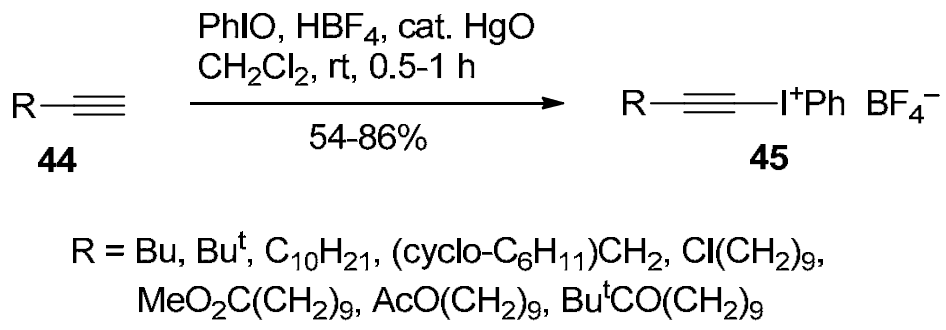

\section{Scheme 17}

Yoshida and coauthors have reported a facile preparation of iodonium salts 47 by the reaction of potassium organotrifluoroborates $\mathbf{4 6}$ with (difluoroiodo)arenes under mild conditions (Scheme 18). ${ }^{11 \mathrm{a}}$ A similar approach to alkynyliodonium salts by the reaction of alkynyldifluoroboranes; polyfluoroorganyliodine difluorides was developed by Frohn and Bardin. ${ }^{11 \mathrm{c}}$

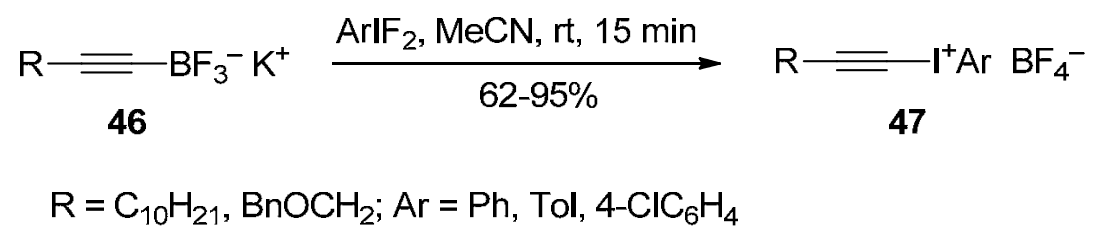

Scheme 18 
Alkynyl(phenyl)iodonium tosylates are commonly prepared by gentle heating of [hydroxy(tosyloxy)iodo]benzene with terminal alkynes in chloroform or dichloromethane. ${ }^{276,28}$ This method is also applicable to the synthesis of alkynyliodonium mesylates and 4nitrobenzenesulfonates by the reaction of the appropriate [hydroxy(organosulfonyloxy)iodo]benzenes with terminal alkynes under similar conditions. ${ }^{28 a}$

The most versatile method of preparation of alkynyl(phenyl)iodonium triflates $\mathbf{5 0}$ employs the iodonium transfer reaction between cyano(phenyl)iodonium triflate $\mathbf{4 9}$ and alkynylstannanes 48 under very mild conditions (Scheme 19). ${ }^{29 a}$ This procedure is particularly useful for the preparation of various complex, functionalized alkynyliodonium derivatives, such as compounds $\mathbf{5 1}, \mathbf{5 2},{ }^{29 \mathrm{~b}} \mathbf{5 3},{ }^{29 \mathrm{c}} \mathbf{5 4},{ }^{29 \mathrm{~d}}$ and $\mathbf{5 5} .{ }^{29 \mathrm{e}}$ Compounds $\mathbf{5 1 - 5 5}$ are formed under these very mild conditions in high yields $(80-90 \%)$ and can be used in subsequent transformations without additional purification.

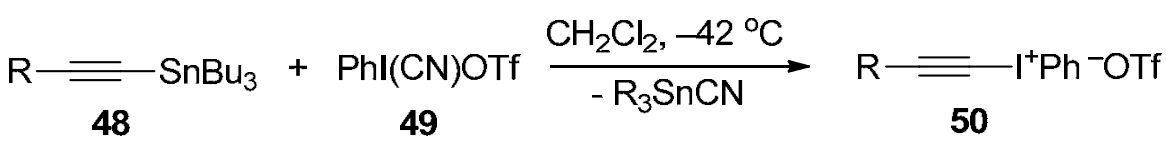

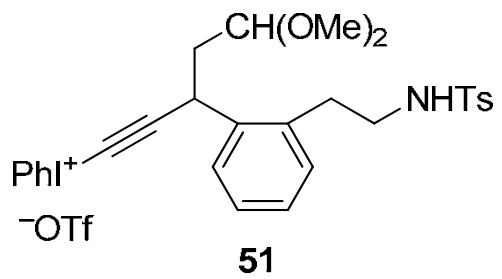
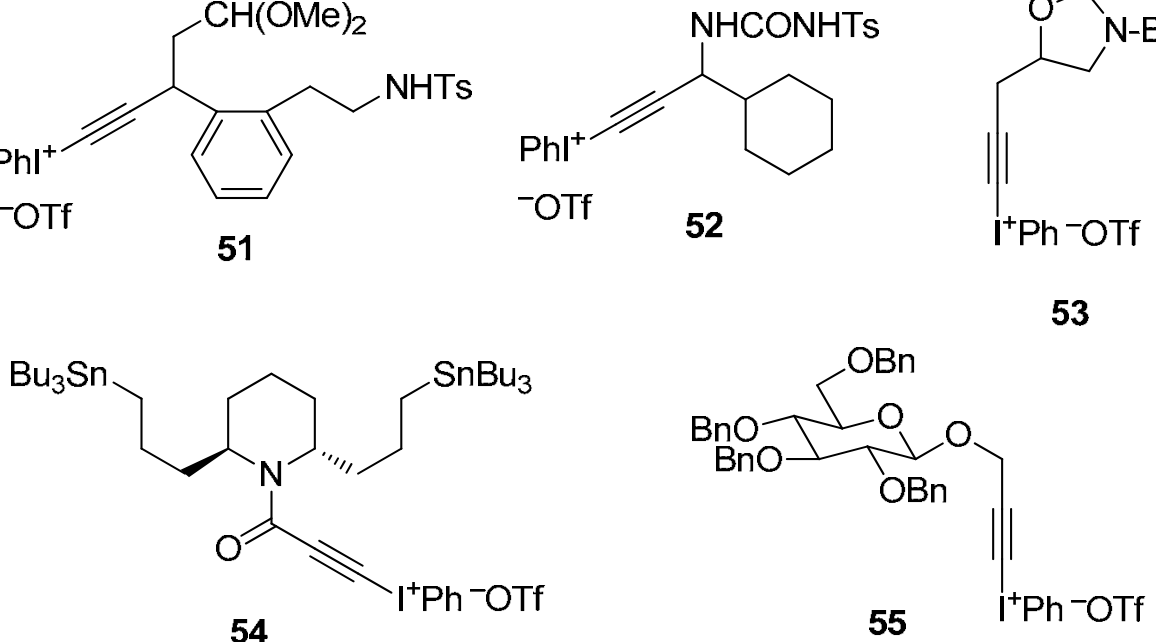

54

\section{Scheme 19}

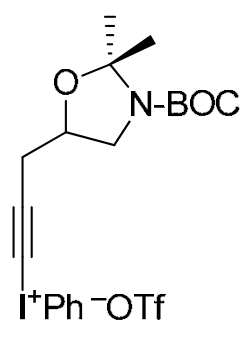

An alternative general procedure for the selective preparation of alkynyl(phenyl)iodonium triflates in moderate yields employs the reaction of alkynylsilanes or alkynylstannanes with Zefirov's reagent, $2 \mathrm{PhIO} \cdot \mathrm{Tf}_{2} \mathrm{O} .^{27 \mathrm{c}, 30 \mathrm{a}}$ This method is also applicable to the synthesis of the parent ethynyl(phenyl)iodonium triflate. ${ }^{30 \mathrm{~b}}$

\subsection{Alkyl(aryl)iodonium salts}

Iodonium salts with one or two aliphatic groups generally lack stability. The presence of electron-withdrawing groups in the alkyl group of iodonium salts has a pronounced stabilizing 
effect. The most stable derivatives of this type are fluoroalkyl(aryl)iodonium salts $\mathbf{5 6}, \mathbf{5 7}$ and (arylsulfonylmethyl)iodonium triflates 58. Iodonium salts $\mathbf{5 6 - 5 8}$ are usually prepared by the reaction of the appropriate bis(trifluoroacetate) like $\mathbf{5 9}$ with benzene in the presence of trifluoromethanesulfonic or other strong acid. The structure of iodonium triflate $\mathbf{5 8}(\mathrm{Ar}=\mathrm{Tol})$ was unambiguously established by a single-crystal X-ray analysis. ${ }^{31 \mathrm{a}}$

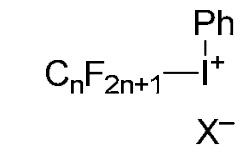

56

$\mathrm{n}=2-8$

$\mathrm{X}=\mathrm{TfO}, \mathrm{HSO}_{4}, \mathrm{FSO}_{3}, \mathrm{MsO}$

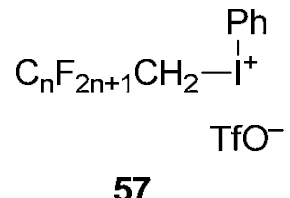

$n=1-3,7$

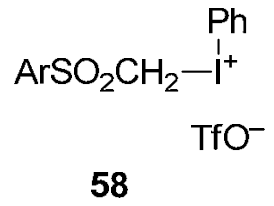

$\mathrm{Ar}=\mathrm{Ph}$ or $p-\mathrm{Tol}$

\section{Scheme 20}

The preparation of fluoroalkyliodonium salts $\mathbf{6 0}$ by the reaction of bis(trifluoroacetates) $\mathbf{5 9}$ with benzene and triflimide acid was reported (Scheme 21). ${ }^{31 \mathrm{~b}-\mathrm{d}}$ The structure of trifluoroethyl(phenyl) iodonium salt $60(n=1)$ was established by a single-crystal X-ray analysis. $^{31 \mathrm{~b}}$ In contrast to fluoroalkyliodonium triflates $\mathbf{5 7}$, compounds $\mathbf{6 0}$ are stable to water and can be used for fluoroalkylations in aqueous media.

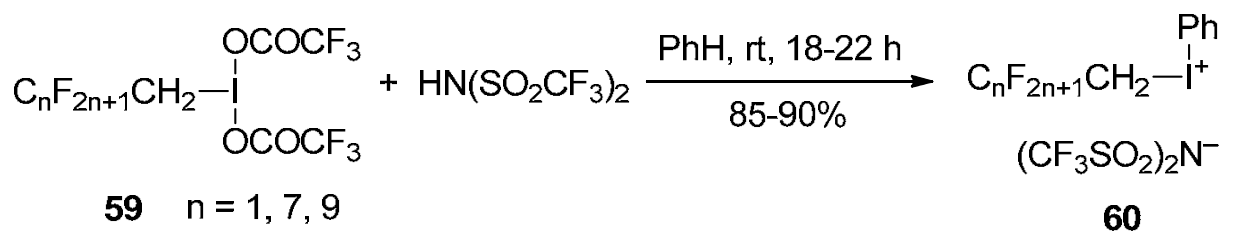

\section{Scheme 21}

\section{Synthetic Applications of Iodonium Salts}

\subsection{Arylations}

The most important and synthetically useful reactions of aryliodonium salts include the direct electrophilic arylations of various nucleophiles, the transition metal mediated cross-coupling reactions, and the reactions involving the generation and trapping of the benzyne intermediates.

Numerous examples of the rections of aryliodonium salts with such nucleophiles as thiosulfonate anions, fluoride anion, malonates, and silyl enol ethers under polar, non-catalytic conditions are provided in our previous reviews. ${ }^{1 \mathrm{j}, \mathrm{u}}$ In more recent papers, the electrophilic arylations of sodium arenesulfinates, ${ }^{32 \mathrm{a}}$ potassium carbonotrithioates, ${ }^{32 \mathrm{~b}}$ and benzazoles ${ }^{32 \mathrm{c}}$ using 
diaryliodonium salts in ionic liquids, and the arylations of anilines, ${ }^{32 \mathrm{~d}}$ sodium tetraphenylborate ${ }^{32 \mathrm{e}}$ and vinylindiums ${ }^{32 \mathrm{f}}$ have been reported.

The mechanism of solvolysis of methoxy-substituted diaryliodonium tetrafluoroborates, $\mathrm{ArI}^{+} \mathrm{Ph}{ }^{-} \mathrm{BF}_{4}$, in methanol and 2,2,2-trifluoroethanol has been investigated. ${ }^{32 \mathrm{~g}}$ The solvolysis products include alkoxide substitution products (ArOR and $\mathrm{PhOR}$ ) as well as iodoarenes ( $\mathrm{PhI}$ and ArI). The ratios of products, ArOR/PhOR, range from 8/2 to 4/6. The results of this study provide experimental evidence against the formation of aryl cation under these conditions and support the pathways via ligand coupling or $\mathrm{S}_{\mathrm{N}} \mathrm{Ar} 2$ mechanisms involving a solvent molecule as a nucleophile in the transition state. ${ }^{32 \mathrm{~g}}$

If the reaction is performed in inert (not nucleophilic) solvent, various nucleophiles may be involved in the reaction with iodonium salt. When diaryliodonium salt reacts with $\mathrm{F}^{-}$anion as nucleophile there is arylfluoride among products. This reaction is widely applied for introduction ${ }^{18} \mathrm{~F}$ isotope into different organic substrates to obtain labeled agents for the positron emission tomography. This topic is separately covered in Section 4.5 hereinafter due to its importance and wide usage.

Arylations of carbon nucleophiles using aryliodonium salts are particularly important. Compounds containing an active methylene group, such as malonates, or the respective carbanions formed in situ, react smoothly with diaryliodonium salts to yield $\alpha$-arylated products. $^{20 \mathrm{~b}, 33}$ Aggarwal and Olofsson have developed a direct asymmetric $\alpha$-arylation of prochiral ketones using chiral lithium amide bases and diaryliodonium salts. ${ }^{20 \mathrm{~b}}$ In a specific example, the deprotonation of cyclohexanone derivative 61 using chiral Simpkins' $(R, R)$-base followed by the reaction with pyridyl iodonium salt gave the arylated product 62 in $94 \%$ enantiomeric excess (Scheme 22). This reaction (Scheme 22) has been employed in a short total synthesis of the alkaloid (-)-epibatidine. ${ }^{20 \mathrm{~b}}$<smiles>O=C1CCC([N+](=O)[O-])CC1</smiles>

61
1.

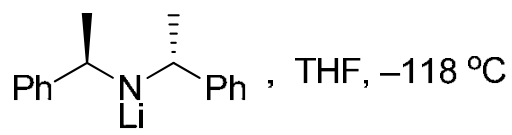

2.

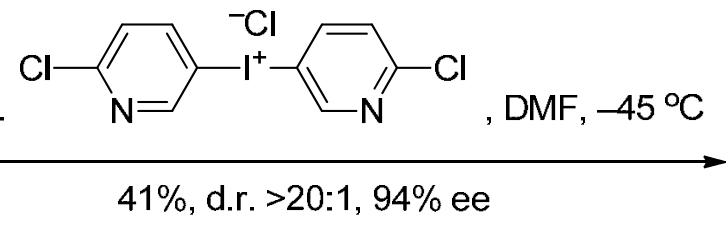<smiles>O=C1CC[C@@H]([N+](=O)[O-])C[C@H]1c1ccc(Cl)nc1</smiles>

62

\section{Scheme 22}

Quideau and co-workers reported a regioselective dearomatizing phenylation of phenols and naphthols using diaryliodonium salts. ${ }^{34 a, b}$ For example, the treatment of naphthols 63 substituted at the ortho position by a small electron-donating group with diphenyliodonium chloride leads to their regioselective ortho-phenylation to give products 64 (Scheme 23). The mechanism of this 
reaction involves a nonradical direct coupling of the ligands on the hypervalent iodine center. ${ }^{34 a}$ The formation of phenol ethers due to the O-phenylation can also occur when the reaction of phenolate anion with diphenyliodonium chloride is carried out in a polar aprotic solvent such as dimethylformamide. ${ }^{34 a}$
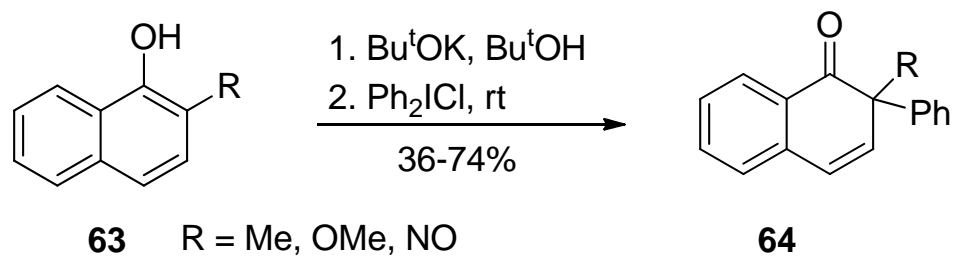

\section{Scheme 23}

Indoles and pyrroles can be efficiently arylated by aryliodonium salts in position 3 in the absence of metal catalysts (Scheme 24). ${ }^{34 c}$ The reaction of unsymmetrically substituted diaryliodonium salts results in the preferential transfer of the less sterically hindered aromatic moiety.
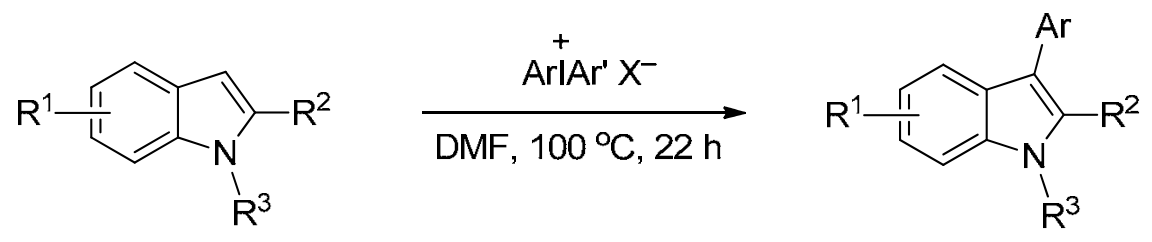

\section{Scheme 24}

Thienyl(phenyl)iodonium salts and other heteroaryl(phenyl)iodonium salts can be used as the selective heteroaryl transfer agents in reactions with phenol ethers. These heteroarylations occur at room temperature in the hexafluoroisopropanol (HFIP) solution in the presence of TMSOTf via SET-mechanism. ${ }^{34 d}$

The O-arylation of the appropriate phenols using symmetrical iodonium salts has been utilized in the synthesis of hydroxylated and methoxylated polybrominated diphenyl ethers, some of which are related to natural products. ${ }^{35 a, b}$ In particular, several polybrominated diphenyl ethers 67 were prepared by the reaction of iodonium salt 65 with phenols 66 in $N, N$-dimethylacetamide solution under basic conditions (Scheme 25). ${ }^{35 a}$ 


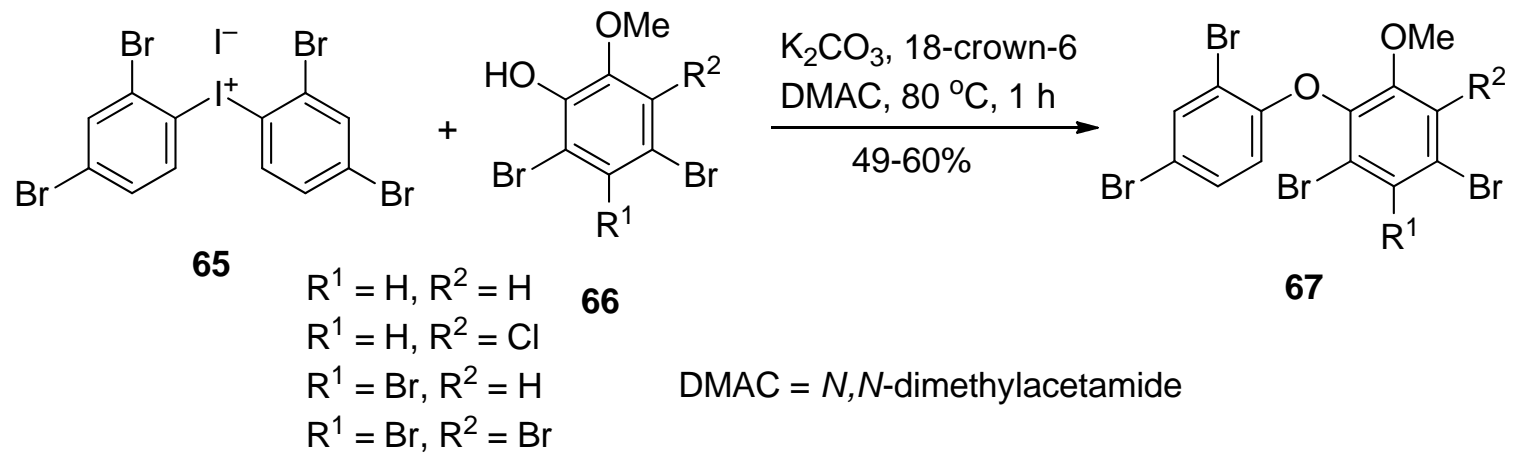

\section{Scheme 25}

Very recently, Olofsson and co-workers have reported a general and high-yielding synthesis of various diaryl ethers using the reaction of diaryliodonium salts with phenols under similar conditions (Scheme 26). The scope of products includes bulky ortho-substituted diaryl ethers, which are difficult to obtain by metal-catalyzed protocols. ${ }^{35 \mathrm{c}}$

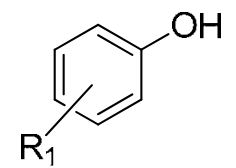

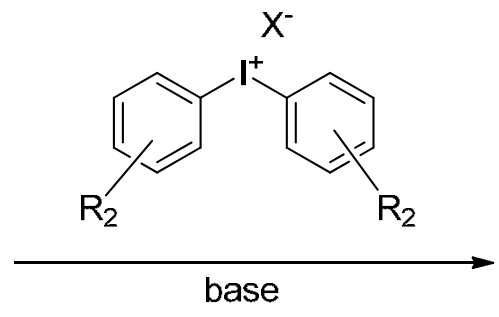

R.T. $2 \mathrm{~h}$ or $40^{\circ} \mathrm{C} 15 \mathrm{~min}$

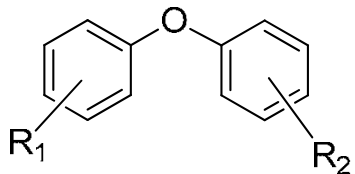

\section{Scheme 26}

Several examples of S-arylation of sulfides and P-arylation of phosphines using diaryliodonium salts were reported in the older literature. ${ }^{35 \mathrm{~d}, \mathrm{e}}$ These reactions generally follow a radical chain mechanism. The arylation of phosphines has been used to effect the photoinitiation of cationic polymerization. ${ }^{35 \mathrm{f}}$

Aryliodonium salts have been found applicable for arylation of carbon surface. ${ }^{36}$ Various iodonium salts can be used as functional groups carriers that allow covering carbon surface by wide range of functional groups, from electron-withdrawing to electron-donating. Properties of modified material are also varied widely.

Arylations with aryliodonium salts can be effectively catalyzed by transition metals. ${ }^{37}$ Aryliodonium salts can serve as efficient reagents in the copper-catalyzed arylation of lithium enolates, ${ }^{37 \mathrm{a}}$ thiophenes, ${ }^{37 \mathrm{~b}}$ 5-aryl-2 $\mathrm{H}$-tetrazole, ${ }^{37 \mathrm{c}}$ uracil nucleosides, ${ }^{37 \mathrm{~d}}$ aniline and phenol derivatives. ${ }^{37 \mathrm{e}}$ Palladium salts and complexes are efficient catalysts in the cross-coupling reactions of diaryliodonium salts with a variety of substrates, ${ }^{37 f-z}$ such as: organoboron compounds, ${ }^{37 \mathrm{f}}$ organostannanes, ${ }^{37 \mathrm{~g}}$ silanes, ${ }^{37 \mathrm{~h}}$ organolead triacetates, ${ }^{37 \mathrm{i}}$ organobismuth(V) derivatives, ${ }^{37 \mathrm{j}}$ carbon monoxide, ${ }^{37 \mathrm{k}}$ allylic alcohols, ${ }^{371}$ functionalized allenes, ${ }^{37 \mathrm{n}, \mathrm{m}}$ Grignard 
reagents, ${ }^{37 \mathrm{o}}$ alkenes, ${ }^{37 \mathrm{p}, \mathrm{q}}$ terminal alkynes, ${ }^{37 \mathrm{r}}$ and arenecarboxylic acids via decarboxylative crosscoupling reaction. ${ }^{37 \mathrm{~s}}$ Particularly interesting is the palladium-catalyzed directed C-H activation/phenylation of substituted 2-phenylpyridines and indoles with aryliodonium salts reported by Sanford and co-workers. ${ }^{10 \mathrm{c}, 37 \mathrm{t}}$ In a representative example, 2-pyridyl substituted substrates 68 are selectively phenylated to the ortho-position affording products 69 in good yields (Scheme 27). Preliminary mechanistic experiments have provided evidence in support of a rare $\mathrm{Pd}(\mathrm{II}) /(\mathrm{IV})$ catalytic cycle for this transformation. ${ }^{10 \mathrm{c}}$ The preparation of stable triorganyl $\mathrm{Pd}(\mathrm{IV})$ complexes by the electrophilic arylation of palladium(II) bipyridine complexes using $\mathrm{Ph}_{2} \mathrm{I}^{+} \mathrm{TfO}^{-}$was reported by Canty and co-workers. ${ }^{37 \mathrm{u}}$ Bedford and co-workers have recently demonstrated that the carbamate $\left(-\mathrm{O}_{2} \mathrm{CNR}_{2}\right)$ function is an excellent directing group for palladium-catalyzed direct arylation reactions using diaryliodonium salts. ${ }^{37 \mathrm{v}}$
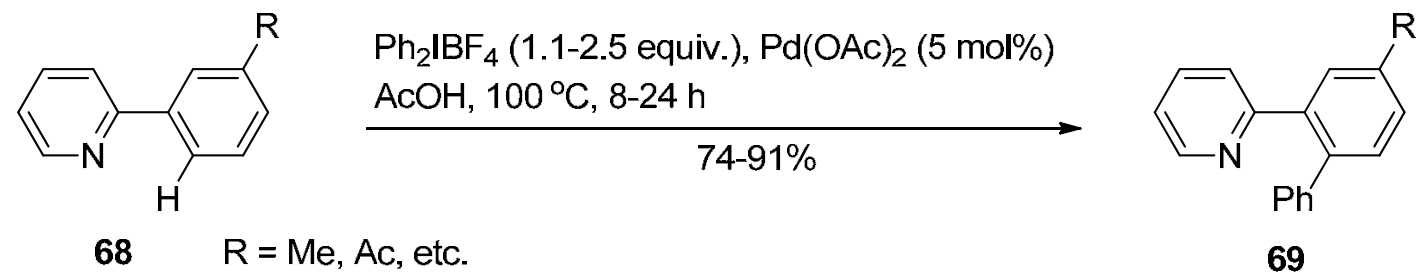

69

\section{Scheme 27}

Kitamura and co-workers reported the preparation and uses of several efficient benzyne precursors based on aryliodonium salts. ${ }^{38}$ In particular, phenyl[2(trimethylsilyl)phenyl]iodonium triflate (70) is readily prepared by the reaction of 1,2bis(trimethylsilyl)benzene with the $\mathrm{PhI}(\mathrm{OAc})_{2} / \mathrm{TfOH}$ reagent system. ${ }^{38 \mathrm{a}}$ The treatment of reagent 70 with tetrabutylammonium fluoride in dichloromethane at room temperature generates benzyne, which can be trapped with a diene to afford the respective benzyne adducts in high yields. $^{38 \mathrm{a}}$ Examples of synthetic application of reagent $\mathbf{7 0}$ as benzyne precursor include Oarylation of carboxylic acids leading to aryl esters 71 , ${ }^{39 a}$ preparation of 2-aryl-substituted nitriles $\mathbf{7 3}$ by arylation of nitriles $\mathbf{7 2}$ via a benzyne reaction, ${ }^{39 b}$ and cycloaddition/elimination reaction of thiophene S-oxide 74 with benzyne leading to product 75 (Scheme 28). ${ }^{39 c}$ Reagent 70 was also used in the synthesis of spiro(imidazolidine-2,3'-benzo[b]thiophene) by a one-pot reaction of benzyne, aryl isothiocyanates and N-heterocyclic carbenes, ${ }^{39 \mathrm{~d}}$ and for the preparation of benzo $[b]$ seleno[2,3-b]pyridines by the reaction of acetic acid 2-selenoxo- $2 \mathrm{H}$-pyridin-1-yl esters with benzyne. ${ }^{39 \mathrm{e}}$ 


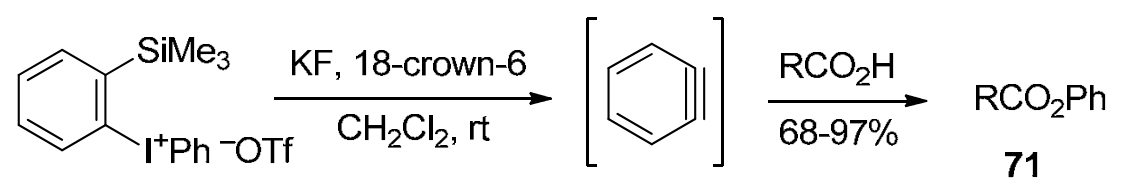

70

$$
\mathrm{R}=\text { alkyl, aryl, alkenyl }
$$

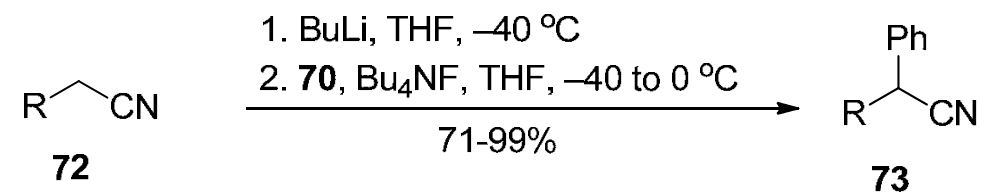

$\mathrm{R}=\mathrm{Me}, \mathrm{Et}, \mathrm{Pr}, \mathrm{Bu}, \mathrm{CN}, \mathrm{CH}_{2} \mathrm{CN}$, etc.<smiles>CC1=C([Al])C([Al])=C(C)S1=O</smiles>

74
70, $\mathrm{Bu}_{4} \mathrm{NF}, \mathrm{THF}, 0^{\circ} \mathrm{C}$ to $\mathrm{rt}$

$55 \%$<smiles>Cc1c(Br)c(Br)c(C)c2ccccc12</smiles>

75

\section{Scheme 28}

The efficient acylbenzyne precursors, [5-acyl-2-(trimethylsilyl)phenyl]iodonium triflates $\mathbf{7 6}$ have been prepared by the reaction of the appropriate 1,2-bis(trimethylsilyl)benzenes with $\mathrm{PhI}(\mathrm{OAc})_{2}$ in the presence of trifluoromethanesulfonic acid in dichloromethane at room temperature. Treatment of these reagents with $\mathrm{Bu}_{4} \mathrm{NF}$ in dichloromethane generates acylbenzynes $\mathbf{7 7}$, which can be trapped by furan to give adducts $\mathbf{7 8}$ in high yield (Scheme 29). ${ }^{38 \mathrm{~d}}$

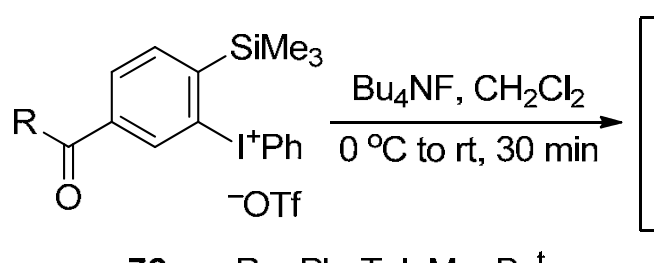

$76 \mathrm{R}=\mathrm{Ph}, \mathrm{Tol}, \mathrm{Me}, \mathrm{Bu}^{\mathrm{t}}$<smiles>[R]C(=O)c1ccccc1CCCCCCC</smiles>

77

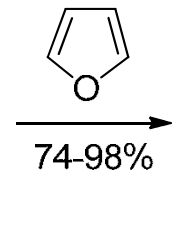

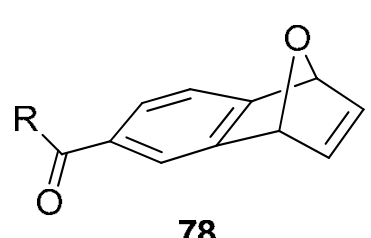

78

\section{Scheme 29}

Lee and co-workers reported the preparation of oxadisilole-substituted benzyne precursors, such as iodonium triflate 80, from benzobisoxadisilole $\mathbf{7 9}$ and the $\mathrm{PhI}(\mathrm{OAc})_{2} / \mathrm{TfOH}$ reagent system. $^{39 \mathrm{f}}$ The treatment of reagent $\mathbf{8 0}$ with $\mathrm{Bu}_{4} \mathrm{NF}$ in $\mathrm{THF}$ and diisopropylamine at room temperature generates oxadisilole-substituted benzyne 81, which can be trapped with furan to afford adduct $\mathbf{8 2}$ in good yield (Scheme 30). 


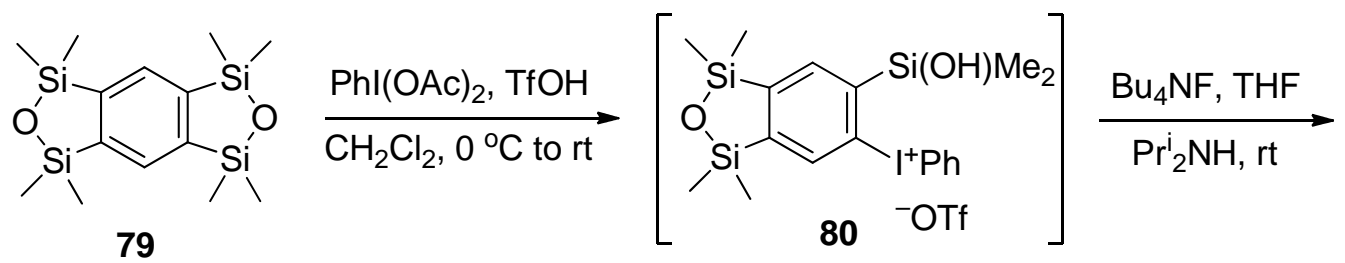

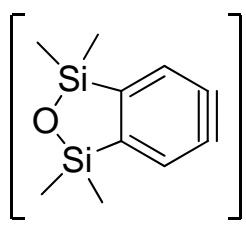

81

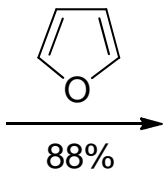

82

\section{Scheme 30}

Ko, Kang and co-workers have reported the generation and trapping of 1,2dehydrocarborane, the carborane analog of benzyne. ${ }^{39 \mathrm{~g}}$ The 1,2-dehydrocarborane precursor, phenyl[o-(trimethylsilyl)carboranyl]iodonium acetate, was readily prepared by the reaction of $[o-$ (trimethylsilyl)carboranyl]lithium and $\mathrm{PhI}(\mathrm{OAc})_{2}$. 1,2-Dehydrocarborane was efficiently generated from phenyl[o-(trimethylsilyl)carboranyl]iodonium acetate by treatment with $\mathrm{CsF}$ in ether and trapped with dienes such as anthracene, naphthalene, norbornadiene and 2,5dimethylfuran to give the respective 1,2-dehydrocarborane adducts in high yield. ${ }^{39 \mathrm{~g}}$

Very recently, McMillan and Allen have accomplished the enantioselective $\alpha$-arylation of aldehydes using diaryliodonium salts and a combination of copper and organic amine catalysts. In a specific example, this new asymmetric protocol has been applied to the rapid synthesis of (S)-ketoprofen, a commercially successful oral and topical analgesic. ${ }^{40}$

\subsection{Alkenylations}

Alkenyl(phenyl)iodonium salts are very reactive compounds because of the excellent leaving group ability of the phenyliodonium moiety $\left(10^{12}\right.$ times greater than for iodine itself) combined with its high electron-withdrawing properties (the Hammett substituent constant $\sigma_{\mathrm{m}}$ for the $\mathrm{PhI}^{+}$ group is 1.35). ${ }^{41 \mathrm{a}}$ Several research groups have been involved in the mechanistic studies of nucleophilic substitution in alkenyliodonium salts. ${ }^{41 b-i}$ Various mechanisms, including $\mathrm{S}_{\mathrm{N}} 1, \mathrm{~S}_{\mathrm{N}} 2$, ligand coupling, and Michael addition-elimination have been observed in these reactions. The mechanistic aspects of the reactions of vinylic iodonium salts with nucleophiles have been reviewed by Okuyama ${ }^{5 \mathrm{~d}}$ and by Ochiai. ${ }^{5 \mathrm{~b}}$

Particularly interesting is the observation of cyclohexyne intermediates 84 as products of $\beta$ elimination in the reactions of 1-cyclohexenyl(phenyl)iodonium salts $\mathbf{8 3}$ with mild bases such as tetrabutylammonium acetate, fluoride ion, alkoxides, and amines in aprotic solvents. ${ }^{41 \mathrm{a}, \mathrm{f}, \mathrm{h}}$ Cyclohexynes 84 could be effectively trapped with tetraphenylcyclopentadienone to give 
products of [4+2] cycloaddition $\mathbf{8 5}$ in high yields (Scheme 31). Cycloheptyne intermediates can be generated under similar conditions from the appropriate iodonium precursors. ${ }^{41 \mathrm{a}, \mathrm{f}, \mathrm{i}}$

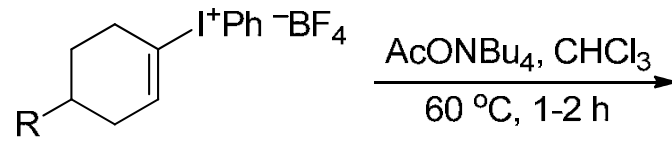

83<smiles>[R]C1CCCCC1CCC</smiles>

84

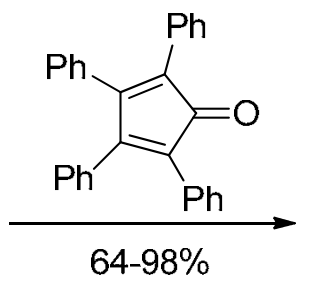

$64-98 \%$ $\mathrm{R}=\mathrm{H}, \mathrm{Me}, \mathrm{Et}, \mathrm{Bu}^{\mathrm{t}}, \mathrm{Ph}, \mathrm{CN}$

\section{Scheme 31}

Alkenyl(phenyl)iodonium salts have found synthetic application as alkenylating reagents in the reactions with various nucleophilic substrates. In most cases these reactions proceed with predominant retention of geometry via the addition-elimination mechanism or ligand coupling on the iodine. Recent examples of alkenylations of nucleophiles under non-catalytic conditions include the stereoselective reactions of alkenyliodonium salts with sodium selenide, sodium sulfide, sodium azide, potassium thiocyanate, ${ }^{42 \mathrm{a}}$ and benzotriazole. ${ }^{42 \mathrm{~b}}$ In a specific example, functionalized beta-enamines $\mathbf{8 6}$ have been prepared by the reaction of polymer-supported alkenyliodonium tosylates $\mathbf{4 1}$ with various nucleophiles at room temperature (Scheme 32 ). ${ }^{26 a}$

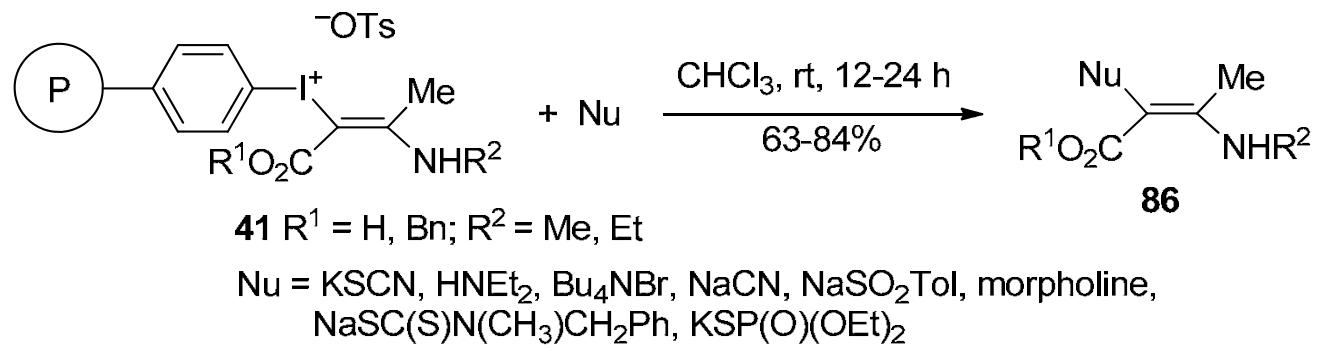

\section{Scheme 32}

$(E)$ - and $(Z)$-(fluoroalkenyl)boronates $\mathbf{8 8 ,} 90$ were prepared stereospecifically by the reaction of $(E)$ - or (Z)-(2-fluoroalkenyl)iodonium salts 87, 89 with di(p-fluorophenoxy)alkylboranes, followed by transesterification to pinacol esters (Scheme 33). The mechanism of this reaction involves the initial generation of 2-fluoroalkylideneiodonium ylide by the $\alpha$-deprotonation of iodonium salts with LDA followed by its reaction with with di(p-fluorophenoxy)alkylboranes. ${ }^{43}$ 


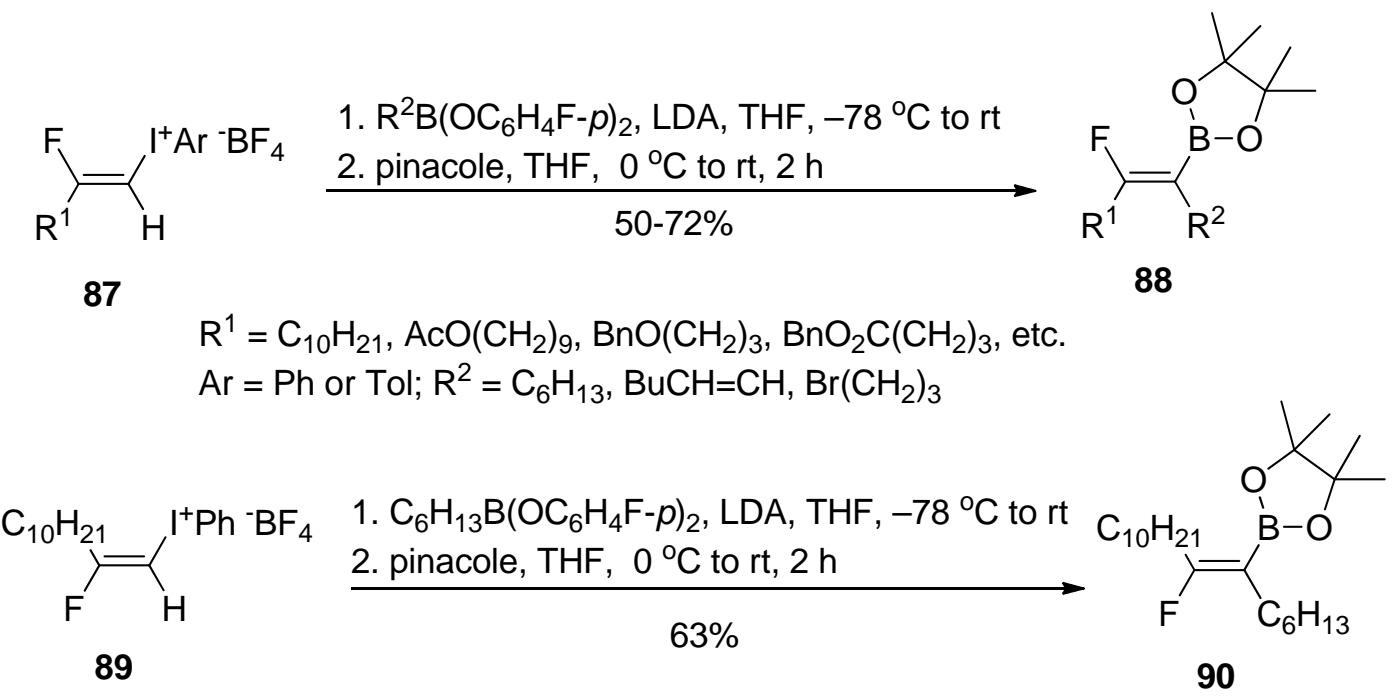

\section{Scheme 33}

Only a few examples of non-catalytic alkenylation of carbon nucleophiles are known. In particular, enolate anions derived from various 1,3-dicarbonyl compounds can be vinylated with cyclohexenyl (91) and cyclopentenyl iodonium salts to afford products 92 (Scheme 34). ${ }^{44}$<smiles>[R]C1([R])C(=O)c2ccccc2C1=O</smiles>

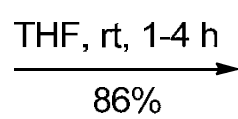<smiles>[R]C1(C2=CCC(Br)CC2)C(=O)c2ccccc2C1=O</smiles>

\section{Scheme 34}

The selectivity of the alkenylation reactions and the yields of products can be dramatically improved by carrying out the reaction of alkenyliodonium salts with carbon nucleophiles in the presence of transition metal compounds in stoichiometric or catalytic amounts. In the presence of a copper(I) catalyst iodonium salts selectively react with iodide anion, ${ }^{24}$ organoborates, ${ }^{45 a}$ Grignard reagents, ${ }^{45 \mathrm{~b}}$ and terminal alkynes ${ }^{45 \mathrm{c}}$ to afford the respective cross-coupling products in high yields with complete retention of geometry. An example of such a reaction is represented by the copper-mediated cross-coupling of H-phosphonates 94 with vinyliodonium salts 93 leading to 2-arylvinylphosphonates 95 under mild conditions (Scheme 35). ${ }^{45 \mathrm{~d}}$ 


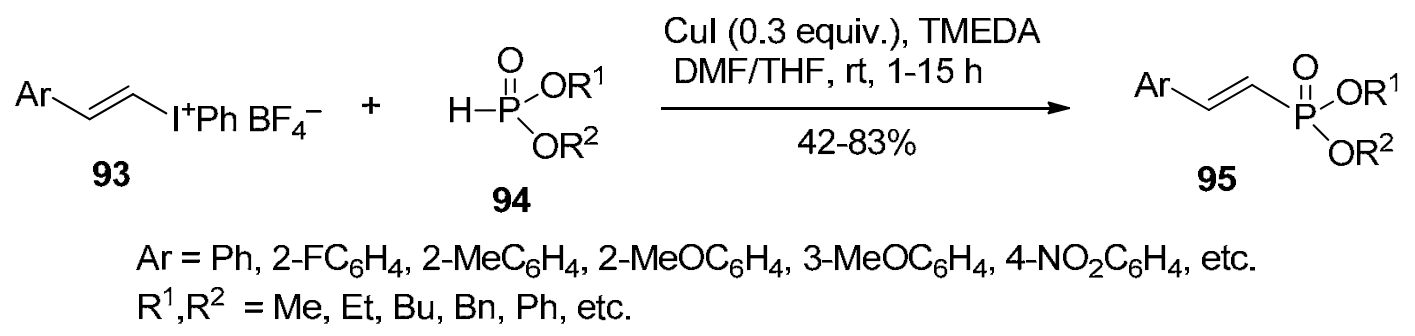

\section{Scheme 35}

Alkenyliodonium salts can be used as highly reactive reagents for Heck-type olefination, ${ }^{46 a, b}$ Sonogashira-type coupling with alkynes, ${ }^{24 a, 46 c}$ and similar palladium-catalyzed cross-coupling reactions. ${ }^{23 a, 24 b, 46 d}$ In a specific example, (Z)- $\beta$-fluoro- $\alpha, \beta$-unsaturated esters 97 were stereoselectively synthesized from (Z)-2-fluoro-1-alkenyliodonium salts 96 by the Pd-catalyzed methoxycarbonylation reaction (Scheme 36). ${ }^{46 \mathrm{~d}}$ The reaction proceeded at room temperature and various functional groups on the substrate can tolerate the reaction conditions.

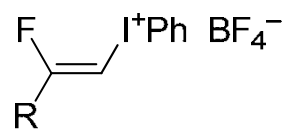

96

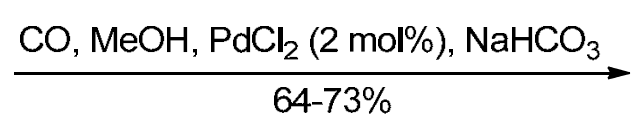

$64-73 \%$

$\mathrm{R}=\mathrm{C}_{10} \mathrm{H}_{21},\left(\right.$ cyclo- $\left.\mathrm{C}_{6} \mathrm{H}_{11}\right) \mathrm{CH}_{2}, \mathrm{Ph}, \mathrm{Cl}\left(\mathrm{CH}_{2}\right)_{9}, \operatorname{Pr}^{\mathrm{i}} \mathrm{O}_{2} \mathrm{C}\left(\mathrm{CH}_{2}\right)_{8}, \mathrm{Bu}^{\mathrm{t}} \mathrm{CO}\left(\mathrm{CH}_{2}\right)_{8}$<smiles>[R]/C(F)=C/C(=O)OC</smiles>

97

\section{Scheme 36}

Reactions of alkenyliodonium salts with strong bases may lead to the generation of an alkylidenecarbene via a base-induced $\alpha$-elimination. Alkylidenecarbenes generated by this method can undergo a 1,5-carbon-hydrogen insertion, providing a useful route for the construction of substituted cyclopentenes. ${ }^{47}$ In a recent example, an efficient synthesis of fluorocyclopentenes 99 by the reaction of (Z)-(2-fluoroalkenyl)iodonium salts 98 with potassium tert-butoxide has been developed (Scheme 37). The mechanism of this reaction involves the initial generation of ( $\alpha$-fluoroalkylidene)carbenes which give fluorocyclopentenes via $1,5-\mathrm{C}-\mathrm{H}$ insertion. ${ }^{47 a}$

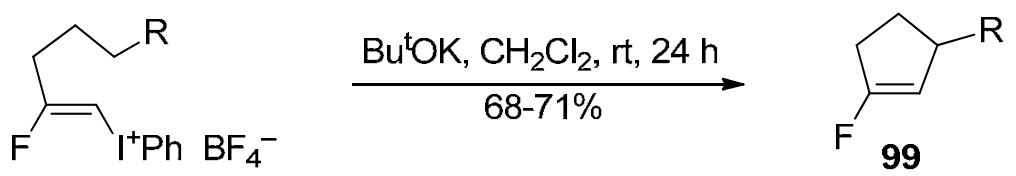

$98 \mathrm{R}=\mathrm{AcO}\left(\mathrm{CH}_{2}\right)_{6}, \mathrm{Cl}\left(\mathrm{CH}_{2}\right)_{6}, \mathrm{Bu}{ }^{\mathrm{t}} \mathrm{CO}\left(\mathrm{CH}_{2}\right)_{5}$, etc.

\section{Scheme 37}




\subsection{Reactions of alkynyl(aryl)iodonium salts}

Reactions of alkynyliodonium salts with nucleophiles proceed via an addition-elimination mechanism involving alkylidene carbenes as key intermediates. Depending on the structure of the alkynyliodonium salt, specific reaction conditions, and the nucleophile employed, this process can lead to a substituted alkyne due to the carbene rearrangement, or to a cyclic product via intramolecular 1,5-carbene insertion. ${ }^{5 a}$ Both of these reaction pathways have been widely utilized in organic synthesis.

Alkynyl(phenyl)iodonium salts have found synthetic application for the preparation of various substituted alkynes by the reaction with the appropriate nucleophiles, such as: enolate anions, ${ }^{30 a, 48 a}$ selenide and telluride anions, ${ }^{48 b-d}$ dialkylphosphonate anions, ${ }^{48}$ benzotriazolate anion, ${ }^{48 \mathrm{f}}$ imidazolate anion, ${ }^{48 \mathrm{~g}} \mathrm{~N}$-functionalized amide anions, ${ }^{48 \mathrm{~h}-\mathrm{j}}$ and transition metal complexes. $^{48 \mathrm{k}-\mathrm{n}}$ Specific recent examples are represented by the preparation of $\mathrm{N}$-alkynyl carbamates 102 by alkynylation of carbamates 100 using alkynyliodonium triflates 101 (Scheme 38), ${ }^{48 \mathrm{i}}$ synthesis of ynamides $\mathbf{1 0 4}$ by the alkynylation/desilylation of tosylanilides $\mathbf{1 0 3}$ using trimethylsilylethynyl(phenyl)iodonium triflate (Scheme 39), ${ }^{48 \mathrm{j}}$ and the preparation of $\operatorname{Ir}(\mathrm{III}) \sigma-$ acetylide complex 106 by the alkynylation of Vaska's complex 105 (Scheme 40). ${ }^{48 \mathrm{k}}$

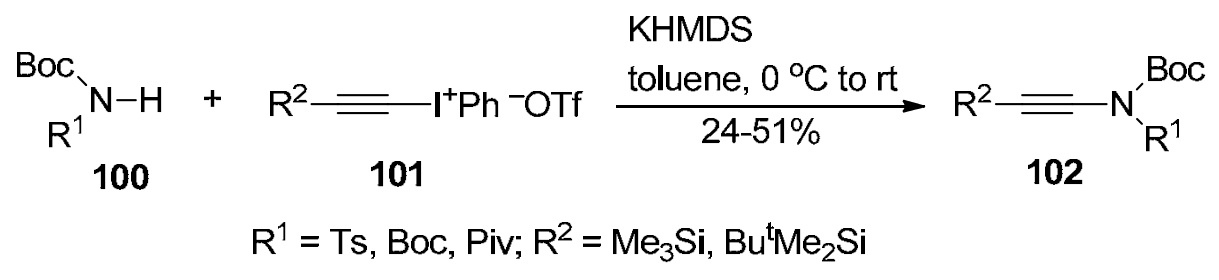

Scheme 38

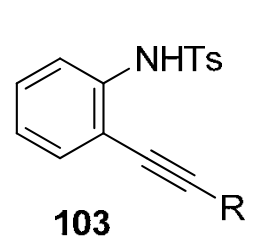

$\mathrm{R}=$ aryl or alkenyl
1. $\mathrm{Cs}_{2} \mathrm{CO}_{3}, \mathrm{DMF}$, rt

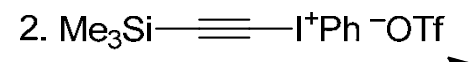

$25-77 \%$

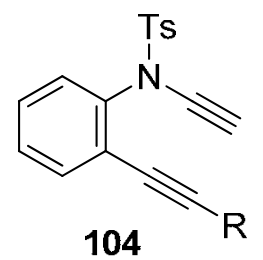

104

Scheme 39

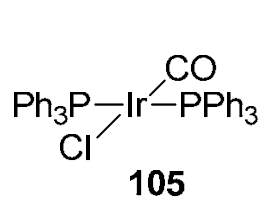

105

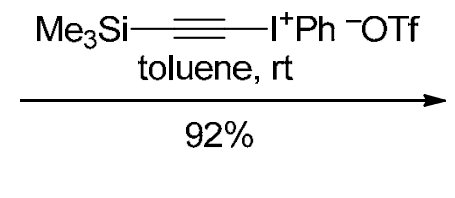

106

\section{Scheme 40}


Alkynyl(phenyl)iodonium salts can be efficiently coupled with organocopper reagents, ${ }^{49 a}$ or with organoboronic acids or organostannanes in the presence of $\mathrm{Cu}(\mathrm{I})$ catalysts. ${ }^{49 \mathrm{~b}, \mathrm{c}}$ Specifically, the copper iodide-catalyzed cross- and carbonylative coupling reactions of alkynyliodonium salts 108 with arylboronic acids $\mathbf{1 0 7}$ or organostannanes 110 under mild conditions afford arylacetylenes 109 and aryl alkynyl ketones 111 in high yields (Scheme 41). ${ }^{49 c}$ Interestingly, alkynyliodonium tetrafluoroborates $\mathbf{1 0 8}$ are more efficient in these coupling reactions than the corresponding iodonium triflates and tosylates.

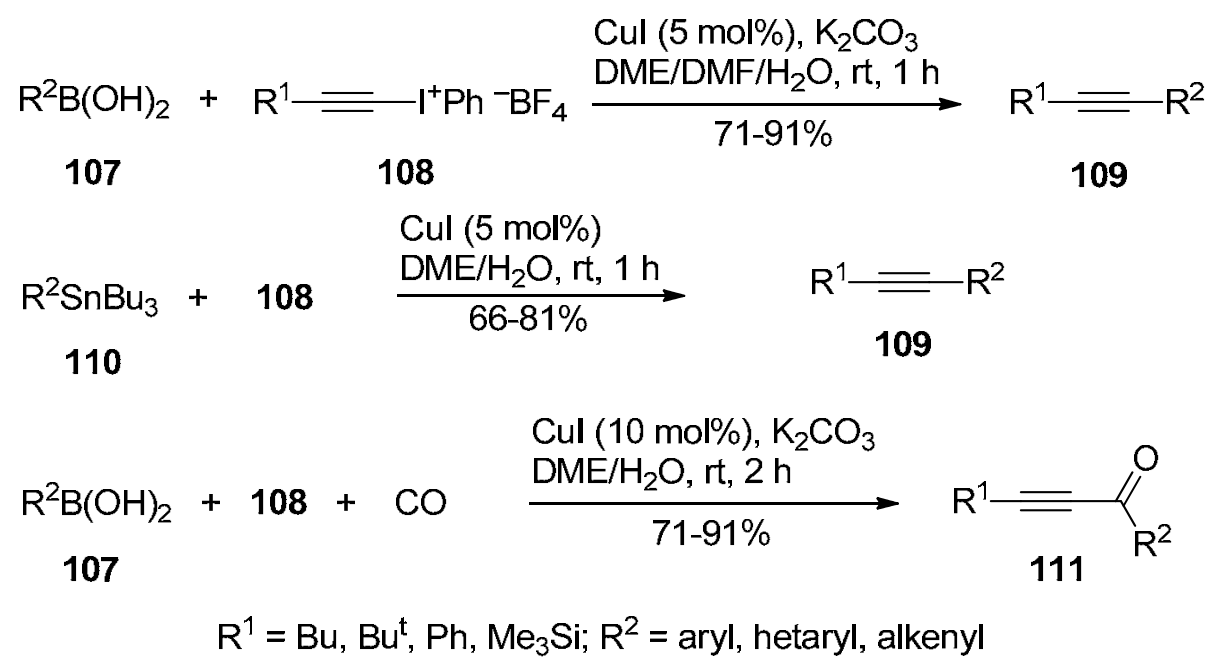

\section{Scheme 41}

A variety of five-membered heterocycles can be prepared efficiently by inter- or intramolecular addition/cyclizations of appropriate nucleophiles with alkynyliodonium salts via alkylidene carbene intermediates. ${ }^{5 \mathrm{a}, 50 \mathrm{a}, \mathrm{b}}$ The intermolecular variant of this cyclization has been utilized in the synthesis of 3-substituted-5,6-dihydroimidazo[2,1-b]thiazoles, ${ }^{50}$ 2-substituted imidazo[1,2-a]pyrimidines, ${ }^{50 \mathrm{~d}}$ and 2-substituted-imidazo[1,2-a]pyridines. ${ }^{50 \mathrm{e}}$ In a specific example, 2-substituted-imidazo[1,2-a]pyridines $\mathbf{1 1 4}$ were synthesized in good yield by cyclocondensation of alkynyl(phenyl)iodonium tosylates 112 with 2-aminopyridine 113 under mild conditions (Scheme 42). The mechanism of this cyclization involves initial nucleophilic addition of the amino group of 2-aminopyridine to the triple bond of the alkynyliodonium salt followed by generation and subsequent cyclization of the intermediate alkylidene carbene. ${ }^{50 \mathrm{e}}$

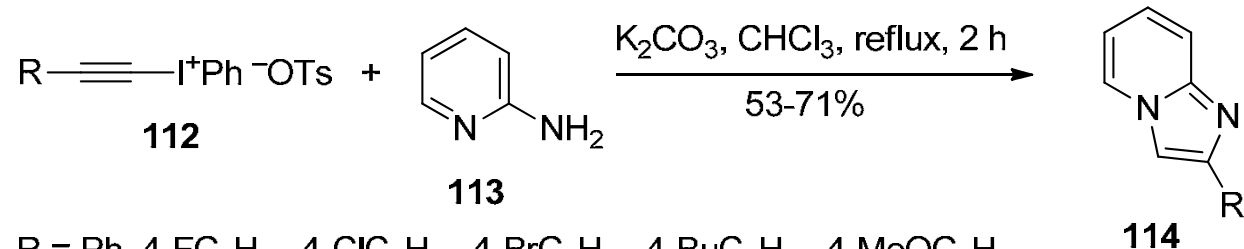

\section{Scheme 42}


Ochiai and co-workers have investigated the mechanism for the one-pot synthesis of 2,4disubstituted thiazoles 117 by cyclocondensation of alkynyliodonium salts 115 with thioureas or thioamides 116 (Scheme 43). ${ }^{51 \text { a }}$ This reaction was originally reported by Wipf and Venkatraman in $1996 .^{51 b}$ Ochiai and co-workers have isolated and identified by X-ray analysis intermediate products 120 (as mesylate or tetrafluoroborate salts), which suggests the mechanism involving Michael addition of sulfur nucleophile 116 to alkynyliodonium salt 115 giving intermediate ylide 118 followed by the 1,2-rearrangement of sulfenyl groups in the resulting alkylidene carbene 119 (Scheme 43). ${ }^{51 \mathrm{a}}$

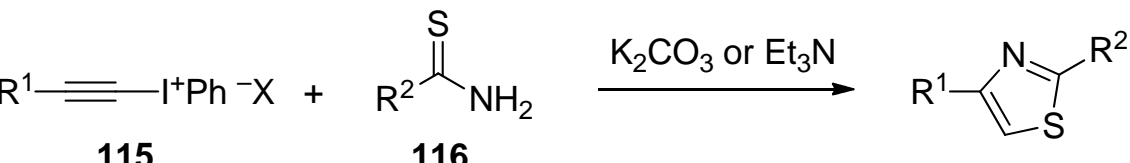

115

116

117

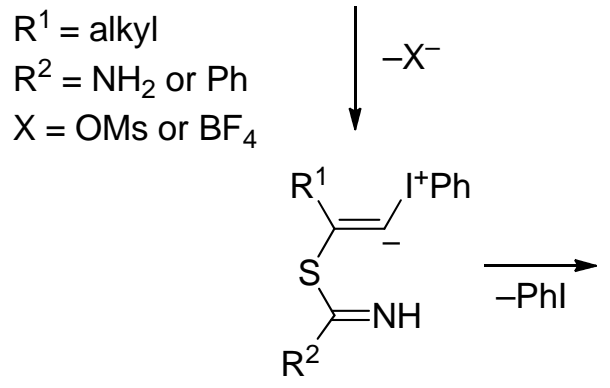

118

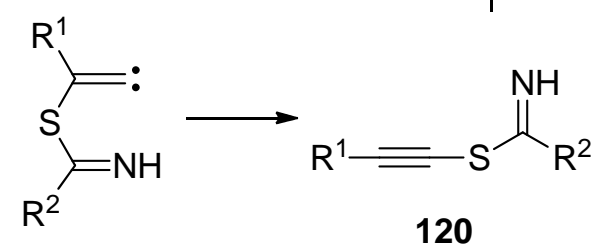

119

\section{Scheme 43}

The intramolecular variant of the alkylidene carbene cyclization is achieved by the treatment of functionalized alkynyliodonium salts with the appropriate nucleophile. Recent examples are represented by the preparation of various functionalized 2,5-dihydrofurans by treatment of 3alkoxy-1-alkynyl(phenyl)iodonium triflates with sodium benzenesulfinate, ${ }^{29}$ by the utilization of the alkylidene carbene cyclization in the total syntheses of natural products agelastatin $\mathrm{A}$ and agelastatin $\mathrm{B},{ }^{29 \mathrm{c}}$ and by the preparation of the tricyclic core of $( \pm)$-halichlorine through the use of an alkynyliodonium salt/alkylidenecarbene/1,5 C-H insertion sequence. ${ }^{29 \mathrm{~d}}$ In particular, Wardrop and Fritz have utilized the sodium benzenesulfinate induced cyclization of the generated in situ alkynyliodonium triflate 121 leading to dihydrofuran 122 (Scheme 44), which is a key intermediate product in the total synthesis of $( \pm)$-magnofargesin. ${ }^{29}$ 


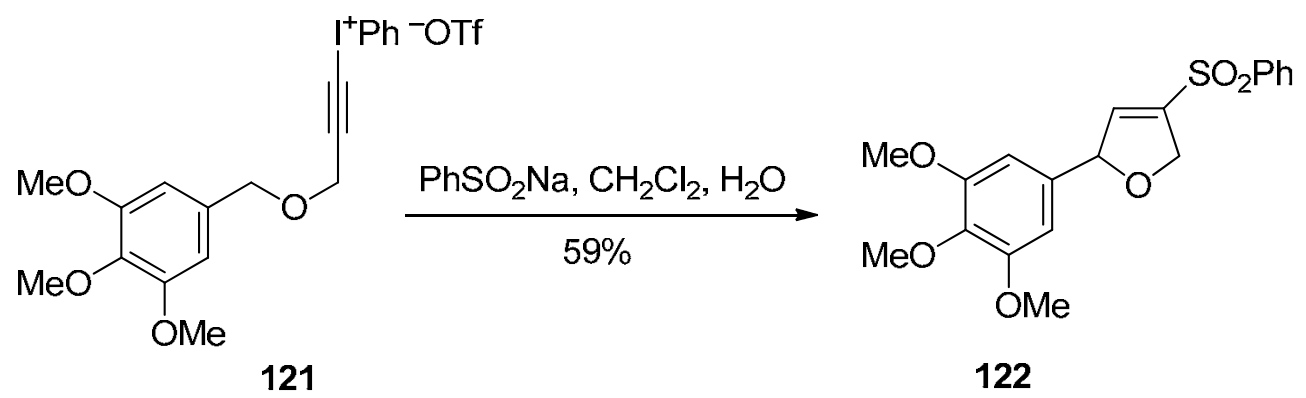

\section{Scheme 44}

Feldman and co-workers have applied the sodium $p$-toluenesulfinate induced cyclizations of alkynyliodonium salts 123 and 54 for the preparation of compounds 124 and 125 (Scheme 45), the key intermediates in the total syntheses of agelastatins ${ }^{29 \mathrm{c}}$ and $( \pm)$-halichlorine, respectively. ${ }^{29 \mathrm{~d}}$

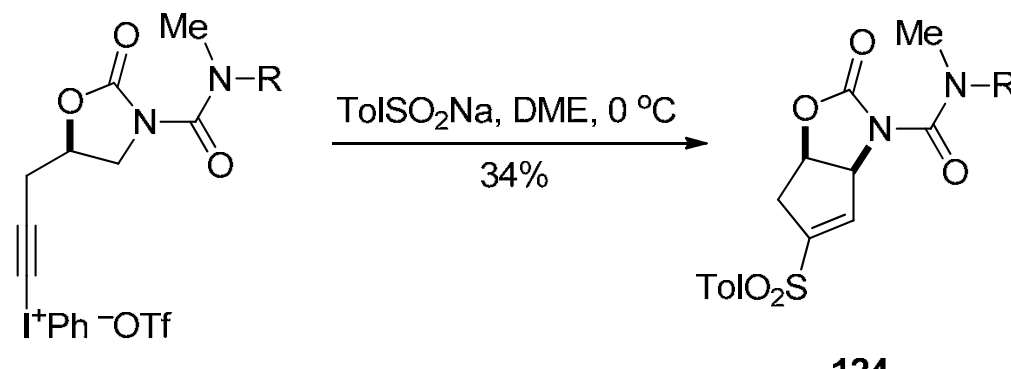

$123 \mathrm{R}=2-\mathrm{NO}_{2} \mathrm{C}_{6} \mathrm{H}_{4} \mathrm{CH}_{2}$

124

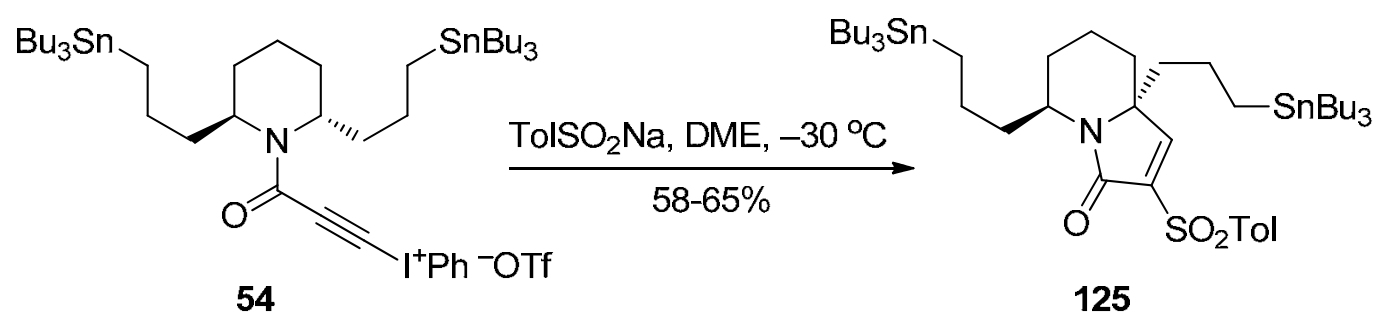

\section{Scheme 45}

\subsection{Alkylations and fluoroalkylations}

Fluoroalkyl(aryl)iodonium triflates 56 and 57 (Section 3.4, Scheme 20) have found practical application as electrophilic fluoroalkylating reagents toward a variety of organic substrates, such as arenes, carbanions, alkynes, alkenes, carbonyl compounds, amines, phosphines, and sulfides. ${ }^{5 \mathrm{~g}}$ For example, trifluoroethyl(phenyl)iodonium triflate $57(\mathrm{n}=1)$ has been used for the $N$ trifluoroethylation of aminoalcohols (Scheme 46). ${ }^{52 \mathrm{a}}$ 
<smiles>OC[C@@H]1CCCN1</smiles>

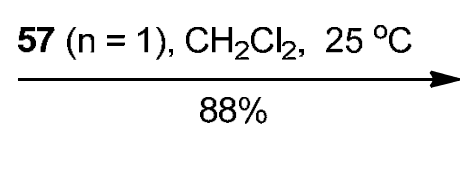<smiles>OC[C@@H]1CCCN1CC(F)(F)F</smiles>

\section{Scheme 46}

Likewise, compounds 60 (Section 3.4, Scheme 21) are useful reagents for fluoroalkylation of amino acids and peptides. ${ }^{31 \mathrm{c}, \mathrm{d}, 52 \mathrm{~b}-\mathrm{e}}$ For example, the reaction of iodonium salt $\mathbf{6 0}(\mathrm{n}=7)$ with the tert-butyl carboxyl ester of tyrosine $\mathbf{1 2 6}$ in the presence of collidine results in quantitative formation of the monoalkylation product 127 (Scheme 47). ${ }^{31 \mathrm{~d}, 52 \mathrm{~d}}$ Due to this reactivity, iodonium salts 60 can be used as fluorous capping reagents for facile purification of peptides synthesized on the solid phase. ${ }^{31 \mathrm{~d}, 52 \mathrm{~d}}$ It was recently demonstrated that iodonium salts $\mathbf{6 0}$ are also useful for the regioselective $\mathrm{N}$ - or C-fluoroalkylation of imidazoles. ${ }^{52 \mathrm{f}}$

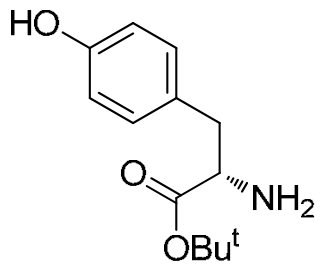

126
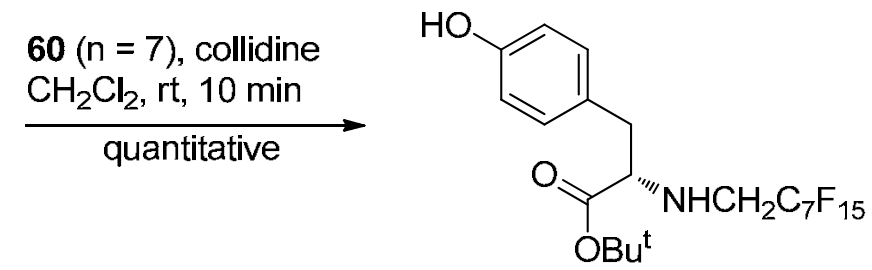

127

\section{Scheme 47}

Similar to fluoroalkyl(aryl)iodonium salts, iodonium salts $\mathbf{5 8}$ are efficient electrophilic alkylating reagents towards a variety of organic nucleophiles (thiophenolate anion, amines, pyridine, triphenyl phosphine, and silyl enol ethers). All these reactions proceed under mild conditions and selectively afforded the appropriate product of alkylation along with iodobenzene as the by-product (Scheme 48). ${ }^{53}$

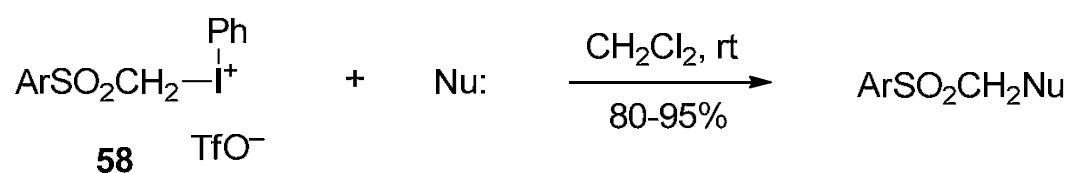$$
\mathrm{Ar}=\mathrm{Ph} \text { or } p-\mathrm{Tol} ; \mathrm{Nu}:=\mathrm{PhS}^{-}, \mathrm{PhO}^{-}, \mathrm{R}_{3} \mathrm{~N}, \mathrm{Ph}_{3} \mathrm{P} \text {, silyl enols, etc. }
$$

\section{Scheme 48}

The unstable $\beta$-oxoalkyl(phenyl)iodonium salts 129 can be generated by a low temperature reaction of silyl enol ethers with reagent $\mathbf{1 2 8}$. These species have been proposed as the reactive 
intermediates in synthetically useful carbon-carbon bond forming reactions with various silyl enol ethers 130 (Scheme 49) and other $\mathrm{C}$-nucleophiles to afford the respective products of $\mathrm{C}-\mathrm{C}$ bond formation. ${ }^{54}$

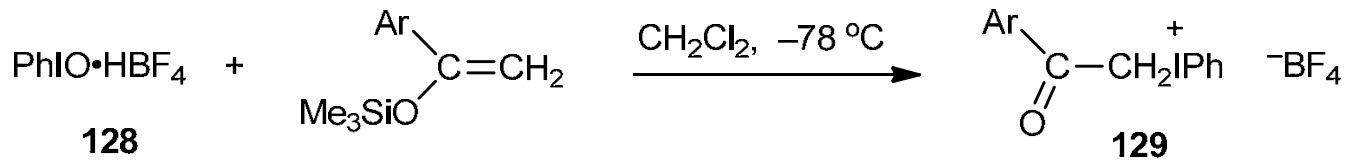

$\mathrm{Ar}=\mathrm{Ph}, 4-\mathrm{MeC}_{6} \mathrm{H}_{4}, 4-\mathrm{ClC}_{6} \mathrm{H}_{4}, 4-\mathrm{NO}_{2} \mathrm{C}_{6} \mathrm{H}_{4}, 4-\mathrm{MeOC}_{6} \mathrm{H}_{4}$<smiles>[R]C(=O)CCC(=O)Br</smiles>

\section{Scheme 49}

\subsection{Introduction of fluorine and application in PET}

${ }^{18} \mathrm{~F}$-labeled imaging agents for positron emission tomography have a short lifetime (due to the short half-life of radioactive decay of ${ }^{18} \mathrm{~F}$ ) and require fast and convenient methods for introduction of ${ }^{18} \mathrm{~F}$ into organic substrate molecules. Reactions of diaryliodonium salts provide such methods (Scheme 46). ${ }^{15 b, 55}$
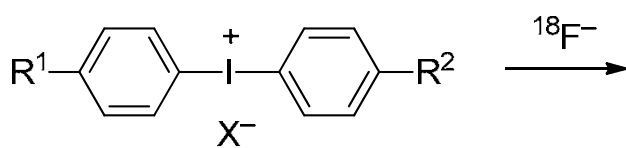<smiles>[R]c1ccc(I)cc1</smiles>

\section{Scheme 50}

In the case of reactions of symmetrical diaryliodonium salts there is no problem with selectivity, however, only half of a molecule of substrate is converted to the target product and the second half gives aryliodide as a byproduct, which results in a low atom economy. Moreover, in this case the problem of separation of aryliodide and arylfluoride may take place due to their similar structure.

One way to eliminate this problem is by appropriate choice of $\mathrm{R}^{1}$ and $\mathrm{R}^{2}$ groups in nonsymmetrical diaryliodonium salts to make the aromatic ring with $\mathrm{R}^{2}$ more electron-rich than the other aryl (Scheme 50). Zhang and coauthors reported a successful synthesis of $\left[{ }^{18} \mathrm{~F}\right] \mathrm{DAA} 1106$ (compound 132) from diaryliodonium salt $\mathbf{1 3 1}$ with the radioactive ${ }^{18} \mathrm{~F}$ anion 
(Scheme 51). ${ }^{55}$ Compound $\mathbf{1 3 2}$ is used as a positron emission tomography (PET) ligand for imaging a peripheral-type benzodiazepine receptor.

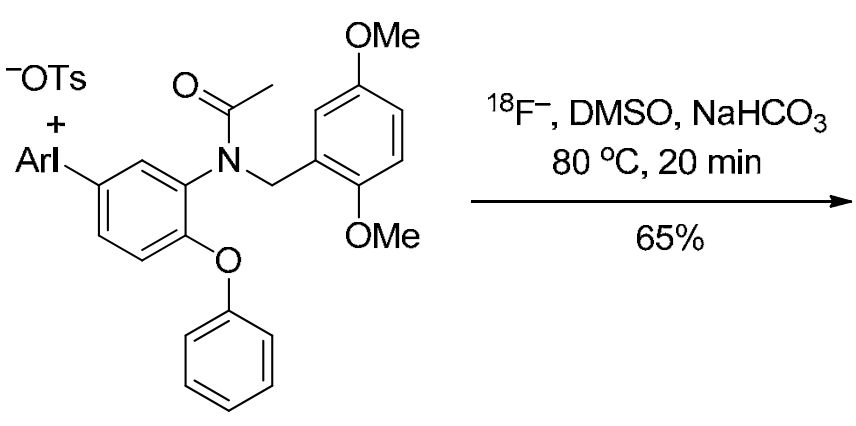

131<smiles>COc1ccc(OC)c(CN(C(C)=O)c2cc(C(F)(F)F)ccc2Oc2ccccc2)c1</smiles>

132

\section{Scheme 51}

Another way uses same idea to make leaving aromatic ring more electron-rich, but it is based on changing the aromatic ring nature instead of $\mathrm{R}^{1}$ and $\mathrm{R}^{2}$ substituents in the phenyl ring. Coenen and coauthors have developed highly efficient fluorination method using aryl-(2thienyl)iodonium salts. ${ }^{55 \mathrm{f}}$ The 2-thienyl group is very electron-rich group that allows ${ }^{18} \mathrm{~F}$ to be introduced directly into electron-rich arenes like anisoles (Scheme 52). ${ }^{55 \mathrm{f}}$

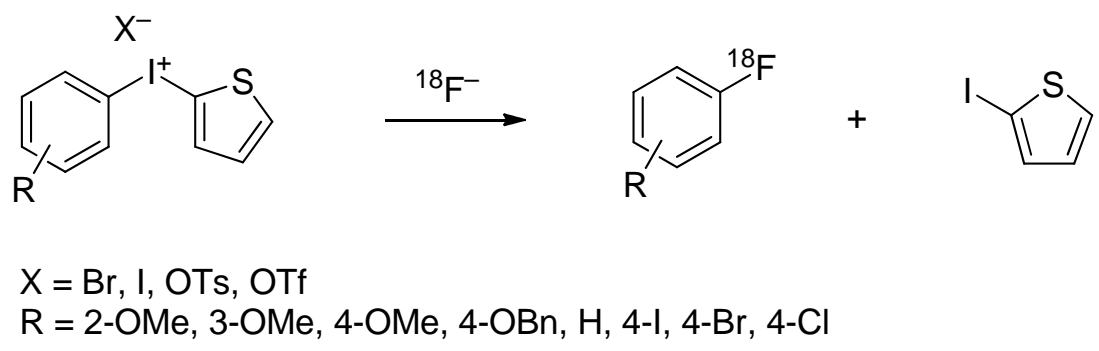

\section{Scheme 52}

DiMagno and co-workers have recently shown that exceptionally electron-rich arene rings can be fluorinated exclusively during the reductive elimination reactions of 5methoxy[2.2]paracyclophan-4-yl diaryliodonium salt 133 (Scheme 53). ${ }^{55 \mathrm{~g}, \mathrm{~h}}$ Use of the sterically hindered cyclophane directing group permits a high degree of control in fluorination reactions of diaryliodonium salts. 


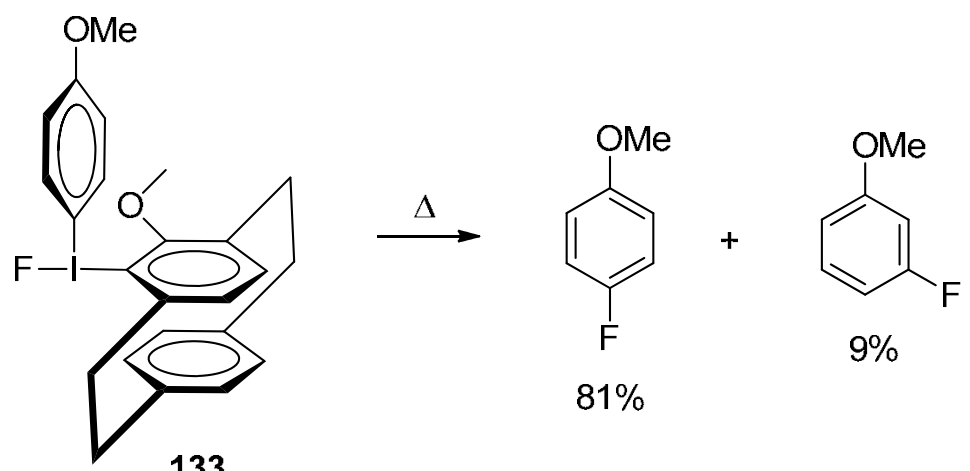

\section{Scheme 53}

Pike and coauthors have developed a microreactor for fluorinations using diaryliodonium salts. This apparatus allows carrying out reaction between the fluoride anion and iodonium salt rapidly and efficiently. ${ }^{55, c}$

\section{Conclusions and Outlook}

This review demonstrates an active current interest in synthetic applications of iodonium salts. This growing interest in hypervalent iodine compounds is mainly due to their very useful reactivity, combined with benign environmental character and commercial availability. Particularly important are the applications of iodonium salts as reagents for mild and highly selective arylations, alkenylations, alkynylations, and alkylations of various organic and inorganic substrates. We anticipate that this area of hypervalent iodine chemistry will continue to attract significant research activity in the future.

\section{Acknowledgements}

Our own work described here was supported by a research grant from the National Science Foundation (CHE-1009038). VVZ and MSY are also thankful to the Government of Russia for support of their cooperative research program on hypervalent iodine chemistry (FCP, GK 02.740.11.5211; Zayavka 2010-1.5-000-010-044).

\section{References and Notes}

1. For books and selected recent reviews on hypervalent iodine chemistry, see. (a) Varvoglis, A. Hypervalent Iodine in Organic Synthesis, Academic Press: London, 1997. (b) Hypervalent Iodine Chemistry; Wirth, T., Ed; Springer-Verlag, Berlin, 2003. (c) Koser G. F. Aldrichimica Acta 2001, 34, 89. (d) Koser, G. F. Adv. Heterocycl. Chem. 2004, 86, 225. (e) Moriarty, R. M. J. Org. Chem. 2005, 70, 2893. (f) Quideau, S.; Pouysegu, L.; Deffieux, D. 
Synlett 2008, 467. (g) Zhdankin, V. V. Curr. Org. Synth. 2005, 2, 121. (h) Ciufolini, M. A.; Braun, N. A.; Canesi, S.; Ousmer, M.; Chang, J.; Chai, D. Synthesis 2007, 3759. (i) Zhdankin, V. V. Science of Synthesis 2007, 31a, Ch. 31.4.1, 161. (j) Zhdankin, V. V.; Stang, P. J. Chem. Rev. 2002, 102, 2523. (k) Ladziata, U.; Zhdankin, V. V. Synlett 2007, 527. (1) Dohi, T.; Kita, Y. Chem. Commun. 2009, 2073. (m) Ochiai, M.; Miyamoto, K. Eur. J. Org. Chem. 2008, 4229. (n) Yusubov, M. S.; Zhdankin, V. V. Mendeleev Commun. 2010, 20, 185. (o) Duschek, A.; Kirsch, S. F. Angew. Chem. Int. Ed. 2011, 50, 1524. (p) Uyanik, M.; Ishihara, K. Chem. Commun. 2009, 2086. (q) Ngatimin, M.; Lupton, D. W. Aust. J. Chem. 2010, 63, 653. (r) Yusubov, M. S.; Nemykin, V. N.; Zhdankin, V. V. Tetrahedron 2010, 66, 5745. (s) Satam, V.; Harad, A.; Rajule, R.; Pati, H. Tetrahedron 2010, 66, 7659. (t) Uyanik, M.; Ishihara, K. Aldrichimica Acta 2010, 43, 83. (u) Zhdankin, V. V.; Stang, P. J. Chem. Rev. 2008, 108, 5299. (v) Merritt, E. A.; Olofsson, B. Synthesis 2011, 517. (w) Brand, J. P.; Gonzalez, D. F.; Nicolai, S.; Waser, J. Chem. Commun. 2011, 47, 102. (x) Liang, H.; Ciufolini, M. A. Chem. Eur. J. 2010, 16, 13262. (y) Zhdankin, V. V. J. Org. Chem. 2011, 76, 1185.

2. Begtrup, M.; Ed. Commemorative Issue in Honor of Prof. Anastasios Varvoglis on the occasion of his 65th anniversary, Arkivoc 2003, (vi), 1-236.

3. For the Symposium-in-Print Tetrahedron issue dedicated to recent advances and applications of hypervalent iodine chemistry in concert with the third International Conference on Hypervalent Iodine Chemistry (ICHCI2010), see: Quideau, S.; Wirth, T. Tetrahedron 2010, 66, 5737.

4. (a) Ladziata, U.; Zhdankin, V. V. Arkivoc 2006, ix, 26. (b) Zhdankin, V. V. Arkivoc 2009, (i), 1 .

5. (a) Zhdankin, V. V.; Stang, P. J. Tetrahedron 1998, 54, 10927. (b) Ochiai, M. J. Organomet. Chem. 2000, 611, 494. (c) Pirkuliev, N. S.; Brel, V. K.; Zefirov, N. S. Russ. Chem. Rev. 2000, 69, 105. (d) Okuyama, T. Acc. Chem. Res. 2002, 35, 12. (e) Merritt, E. A.; Olofsson, B. Angew. Chem., Int. Ed. 2009, 48, 9052. (f) Grushin, V. V. Chem. Soc. Rev. 2000, 29, 315. (g) Umemoto, T. Chem. Rev. 1996, 96, 1757.

6. Okuyama, T.; Takino, T.; Sueda, T.; Ochiai, M. J. Am. Chem. Soc. 1995, 117, 3360.

7. (a) Shirai, A.; Kubo, H.; Takahashi, E. J. Photopolym. Sci. Technol. 2002, 15, 29. (b) VanderHart, D. L.; Prabhu, V. M.; Lin, E. K. Chem. Mater. 2004, 16, 3074. (c) Slegt, M.; Minne, F.; Zuilhof, H.; Overkleeft, H. S.; Lodder, G. Eur. J. Org. Chem. 2007, 5353. (d) Tasdelen, M. A.; Kumbaraci, V.; Jockusch, S.; Turro, N. J.; Talinli, N.; Yagci, Y. Macromolecules 2008, 41, 295. (e) Crivello, J. V. J. Polym. Sci., Part A Polym. Chem. 2009, 47, 866. (f) Crivello, J. V. J. Polym. Sci., Part A Polym. Chem. 2009, 47, 1825. (g) Bulut, U.; Gunbas, G. E.; Toppare, L. J. Polym. Sci., Part A Polym. Chem. 2010, 48, 209. (h) Ortiz, R. A.; Santos, R. G.; Duarte, L. B.; Alvarez, E. A. P.; Romero, J. N. C.; Valdez, A. E. G. J. Appl. Polym. Sci. 2008, 108, 598.

8. Stang, P. J.; Zhdankin, V. V. Chem. Rev. 1996, 96, 1123. 
9. Goldstein, E. J. C.; Citron, D. M.; Warren, Y.; Merriam, C. V.; Tyrrell, K.; Fernandez, H.; Radhakrishnan, U.; Stang, P. J.; Conrads, G. Antimicrobial Agents and Chemotherapy 2004, 48, 2766.

10. (a) Crivello, J. V.; Lam, J. H. W. Macromolecules 1977, 10, 1307. (b) Ochiai, M.; Toyonari, M.; Sueda, T.; Kitagawa, Y. Tetrahedron Lett. 1996, 37, 8421. (c) Chen, D.-W.; Ochiai, M. J. Org. Chem. 1999, 64, 6804. (d) Kalyani, D.; Deprez, N. R.; Desai, L. V.; Sanford, M. S. J. Am. Chem. Soc. 2005, 127, 7330.

11. (a) Yoshida, M.; Osafune, K.; Hara, S. Synthesis 2007, 1542. (b) Abo-Amer, A.; Frohn, H.J.; Steinberg, C.; Westphal, U. J. Fluorine Chem. 2006, 127, 1311. (c) Frohn, H.-J.; Bardin, V. V. Z. Anorg. Allg. Chem. 2008, 634, 82.

12. Ochiai, M.; Ito, T.; Takaoka, Y.; Masaki, Y. J. Am. Chem. Soc. 1991, 113, 1319.

13. Helber, J.; Frohn, H.-J.; Klose, A.; Scholten, T. Arkivoc 2003, vi, 71.

14. (a) Dohi, T.; Ito, M.; Morimoto, K.; Minamitsuji, Y.; Takenaga, N.; Kita, Y. Chem. Commun. 2007, 4152. (b) Koser, G. F.; Wettach, R. H. J. Org. Chem. 1980, 45, 1542. (c) Carman, C. S.; Koser, G. F. J. Org. Chem. 1983, 48, 2534. (d) Pike, V. W.; Butt, F.; Shah, A.; Widdowson, D. A. J. Chem. Soc., Perkin Trans. 1 1999, 245. (e) Zhang, M.-R.; Kumata, K.; Suzuki, K. Tetrahedron Lett. 2007, 48, 8632. (f) Lee, B. C.; Lee, K. C.; Lee, H.; Mach, R. H.; Katzenellenbogen, J. A. Bioconjugate. Chem. 2007, 18, 514. (g) Carroll, M. A.; Pike, V. W.; Widdowson, D. A. Tetrahedron Lett. 2000, 41, 5393.

15. (a) Kitamura, T.; Matsuyuki, J.; Nagata, K.; Furuki, R.; Taniguchi, H. Synthesis 1992, 945.

(b) Shah, A.; Pike, V. W.; Widdowson, D. A. J. Chem. Soc., Perkin Trans. 1 1997, 2463. (c) Kitamura, T.; Inoue, D.; Wakimoto, I.; Nakamura, T.; Katsuno, R.; Fujiwara, Y. Tetrahedron 2004, 60, 8855 .

16. (a) Hossain, M. D.; Kitamura, T. Tetrahedron 2006, 62, 6955. (b) Hossain, M. D.; Ikegami, Y.; Kitamura, T. J. Org. Chem. 2006, 71, 9903. (c) Hossain, M. D.; Kitamura, T. Bull. Chem. Soc. Jpn. 2007, 80, 2213. (d) Bielawski, M.; Zhu, M.; Olofsson, B. Adv. Synth. Catal. 2007, 349, 2610. (e) Bielawski, M.; Olofsson, B. J. Chem. Soc., Chem. Commun. 2007, 2521. (f) Zhu, M.; Jalalian, N.; Olofsson, B. Synlett 2008, 592. (g) Bielawski, M.; Aili, D.; Olofsson, B. J. Org. Chem. 2008, 73, 4602. (h) Jalalian, N.; Olofsson, B. Tetrahedron 2010, 66, 5793. (i) Merritt, E. A.; Malmgren, J.; Klinke, F. J.; Olofsson, B. Synlett 2009, 2277. (j) Dohi, T.; Yamaoka, N.; Itani, I.; Kita, Y. Aust. J. Chem. 2011, 64, 529. (k) Dohi, T.; Yamaoka, N.; Kita, Y. Tetrahedron 2010, 66, 5775.

17. Kraszkiewicz, L.; Skulski, L. Synthesis 2008, 2373.

18. (a) Zhdankin, V. V.; Scheuller, M. C.; Stang, P. J. Tetrahedron Lett. 1993, 34, 6853. (b) Gallop, P. M.; Paz, M. A.; Fluckiger, R.; Stang, P. J.; Zhdankin, V. V.; Tykwinski, R. R. J. Am. Chem. Soc. 1993, 115, 11702. (c) Stang, P. J.; Tykwinski, R.; Zhdankin, V. J. Heterocycl. Chem. 1992, 29, 815. (d) Stang, P. J.; Zhdankin, V. V.; Tykwinski, R.; Zefirov, N. S. Tetrahedron Lett. 1992, 33, 1419. (e) Bykowski, D.; McDonald, R.; Hinkle, R. J.; Tykwinski, R. R. J. Org. Chem. 2002, 67, 2798. 
19. (a) Radhakrishnan, U.; Stang, P. J. J. Org. Chem. 2003, 68, 9209. (b) Stang, P. J.; Zhdankin, V. V. J. Am. Chem. Soc. 1993, 115, 9808.

20. (a) Stang, P. J.; Olenyuk, B.; Chen, K. Synthesis 1995, 937. (b) Aggarwal, V. K.; Olofsson, B. Angew. Chem., Int. Ed. 2005, 44, 5516. (c) Beringer, F. M.; Nathan, R. A. J. Org. Chem. 1970, 35, 2095. (d) Beringer, F. M.; Nathan, R. A. J. Org. Chem. 1969, 34, 685. (e) Stang, P. J.; Chen, K. J. Am. Chem. Soc. 1995, 117, 1667.

21. (a) Ochiai, M.; Sumi, K.; Takaoka, Y.; Kunishima, M.; Nagao, Y.; Shiro, M.; Fujita, E. Tetrahedron 1988, 44, 4095. (b) Ochiai, M.; Sueda, T.; Noda, R.; Shiro, M. J. Org. Chem. 1999, 64, 8563.

22. (a) Ochiai, M.; Toyonari, M.; Nagaoka, T.; Chen, D.-W.; Kida, M. Tetrahedron Lett. 1997, 38, 6709. (b) Fujita, M.; Lee, H. J.; Okuyama, T. Org. Lett. 2006, 8, 1399.

23. (a) Yoshida, M.; Kawakami, K.; Hara, S. Synthesis 2004, 2821. (b) Kasumov, T. M.; Pirguliyev, N. S.; Brel, V. K.; Grishin, Y. K.; Zefirov, N. S.; Stang, P. J. Tetrahedron 1997, 53, 13139. (c) Hinkle, R. J.; Thomas, D. B. J. Org. Chem. 1997, 62, 7534. (d) Pirguliyev, N. S.; Brel, V. K.; Akhmedov, N. G.; Zefirov, N. S. Synthesis 2000, 81.

24. (a) Yoshida, M.; Hara, S. Org. Lett. 2003, 5, 573. (b) Yoshida, M.; Komata, A.; Hara, S. Tetrahedron 2006, 62, 8636.

25. (a) Hinkle, R. J.; Stang, P. J. Synthesis 1994, 313. (b) McNeil, A. J.; Hinkle, R. J.; Rouse, E. A.; Thomas, Q. A.; Thomas, D. B. J. Org. Chem. 2001, 66, 5556.

26. (a) Chen, J.-M.; Huang, X. Synlett 2004, 552. (b) Zhang, P.; Chen, Z. J. Chem. Res. (S) 2003, 570.

27. (a) Ochiai, M.; Kunishima, M.; Sumi, K.; Nagao, Y.; Fujita, E.; Arimoto, M.; Yamaguchi, H. Tetrahedron Lett. 1985, 26, 4501. (b) Rebrovic, L.; Koser, G. F. J. Org. Chem. 1984, 49, 4700. (c) Koumbis, A. E.; Kyzas, C. M.; Savva, A.; Varvoglis, A. Molecules 2005, 10, 1340. (d) Yoshida, M.; Nishimura, N.; Hara, S. Chem. Commun. 2002, 1014.

28. (a) Stang, P. J.; Surber, B. W.; Chen, Z. C.; Roberts, K. A.; Anderson, A. G. J. Am. Chem. Soc. 1987, 109, 228. (b) Kitamura, T.; Lee, C. H.; Taniguchi, H.; Matsumoto, M.; Sano, Y. J. Org. Chem. 1994, 59, 8053.

29. (a) Stang, P. J.; Williamson, B. L.; Zhdankin, V. V. J. Am. Chem. Soc. 1991, 113, 5870. (b) Feldman, K. S.; Bruendl, M. M.; Schildknegt, K.; Bohnstedt, A. C. J. Org. Chem. 1996, 61, 5440. (c) Feldman, K. S.; Saunders, J. C.; Wrobleski, M. L. J. Org. Chem. 2002, 67, 7096. (d) Feldman, K. S.; Perkins, A. L.; Masters, K. M. J. Org. Chem. 2004, 69, 7928. (e) Wardrop, D. J.; Fritz, J. Org. Lett. 2006, 8, 3659.

30. (a) Bachi, M. D.; Bar-Ner, N.; Crittell, C. M.; Stang, P. J.; Williamson, B. L. J. Org. Chem. 1991, 56, 3912. (b) Stang, P. J.; Arif, A. M.; Crittell, C. M. Angew. Chem. Int. Ed. 1990, 29, 287.

31. (a) Zhdankin, V. V.; Erickson, S. A.; Hanson, K. J. J. Am. Chem. Soc. 1997, 119, 4775. (b) Montanari, V.; DesMarteau, D. D.; Pennington, W. T. J. Mol. Str. 2000, 550-551, 337. (c) DesMarteau, D. D.; Montanari, V. J. Chem. Soc., Chem. Commun. 1998, 2241. (d) Montanari, V.; Kumar, K. J. Am. Chem. Soc. 2004, 126, 9528. 
32. (a) Wang, F.-Y.; Chen, Z.-C.; Zheng, Q.-G. J. Chem. Res. (S) 2003, 620. (b) Wang, F.-Y.; Chen, Z.-C.; Zheng, Q.-G. J. Chem. Res. (S) 2003, 810. (c) Wang, F.-Y.; Chen, Z.-C.; Zheng, Q.-G. J. Chem. Res. 2004, 206. (d) Carroll, M. A.; Wood, R. A. Tetrahedron 2007, 63, 11349. (e) Yan, J.; Hu, W.; Rao, G. Synthesis 2006, 943. (f) Xue, Z.; Yang, D.; Wang, C. J. Organomet. Chem. 2006, 691, 247. (g) Fujita, M.; Mishima, E.; Okuyama, T. J. Phys. Org. Chem. 2007, 20, 241.

33. (a) Oh, C. H.; Kim, J. S.; Jung, H. H. J. Org. Chem. 1999, 64, 1338. (b) Ochiai, M.; Kitagawa, Y.; Takayama, N.; Takaoka, Y.; Shiro, M. J. Am. Chem. Soc. 1999, 121, 9233. (c) Norrby, P.-O.; Petersen, T. B.; Bielawski, M.; Olofsson, B. Chem.- Eur. J. 2010, 16, 8251.

34. (a) Ozanne-Beaudenon, A.; Quideau, S. Angew. Chem., Int. Ed. 2005, 44, 7065. (b) Quideau, S.; Pouysegu, L.; Ozanne, A.; Gagnepain, J. Molecules 2005, 10, 201. (c) Ackermann, L.; Dell'Acqua, M.; Fenner, S.; Vicente, R.; Sandmann, R. Org. Lett. 2011, 13, 2358. (d) Dohi, T.; Ito, M.; Yamaoka, N.; Morimoto, K.; Fujioka, H.; Kita, Y. Angew. Chem. Int. Ed. 2010, 49, 3334.

35. (a) Marsh, G.; Stenutz, R.; Bergman, A. Eur. J. Org. Chem. 2003, 2566. (b) Couladouros, E. A.; Moutsos, V. I.; Pitsinos, E. N. Arkivoc 2003, xv, 92. (c) Jalalian, N.; Ishikawa, E. E.; Silva, L. F.; Olofsson, B. Org. Lett. 2011, 13, 1552. (d) Ptitsyna, O. A.; Pudeeva, M. E.; Reutov, O. A. Dokl. Akad. Nauk SSSR 1965, 165, 582. (e) Kampmeier, J. A.; Nalli, T. W. J. Org. Chem. 1993, 58, 943. (f) Muneer, R.; Nalli, T. W. Macromolecules 1998, 31, 7976.

36. (a) Vase, K. H.; Holm, A. H.; Norrman, K.; Pedersen, S. U.; Daasbjerg, K. Langmuir 2007, 23, 3786. (b) Weissmann, M.; Baranton, S.; Coutanceau, C. Langmuir 2010, 26, 15002.

37. (a) Ryan, J. H.; Stang, P. J. Tetrahedron Lett. 1997, 38, 5061. (b) Zhang, B.-X.; Nuka, T.; Fujiwara, Y.; Yamaji, T.; Hou, Z.; Kitamura, T. Heterocycles 2004, 64, 199. (c) Zhou, T.; Chen, Z.-C. J. Chem. Res. 2004, 404. (d) Zhou, T.; Li, T.-C.; Chen, Z.-C. Helv. Chim. Acta 2005, 88, 290. (e) Ciana, C.-L.; Phipps, R. J.; Brandt, J. R.; Meyer, F.-M.; Gaunt, M. J. Angew. Chem. Int. Ed. 2011, 50, 458. (f) Bumagin, N. A.; Tsarev, D. A. Tetrahedron Lett. 1998, 39, 8155. (g) Al-Qahtani, M. H.; Pike, V. W. J. Chem. Soc., Perkin Trans. 1 2000, 1033. (h) Kang, S.-K.; Yamaguchi, T.; Ho, P.-S.; Kim, W.-Y.; Yoon, S.-K. Tetrahedron Lett. 1997, 38, 1947. (i) Kang, S.-K.; Choi, S.-C.; Baik, T.-G. Synth. Commun. 1999, 29, 2493. (j) Kang, S.-K.; Ryu, H.-C.; Kim, J.-W. Synth. Commun. 2001, 31, 1021. (k) Kang, S.-K.; Yamaguchi, T.; Ho, P.-S.; Kim, W.-Y.; Ryu, H.-C. J. Chem. Soc., Perkin Trans. 1 1998, 841. (1) Kang, S.-K.; Lee, H.-W.; Jang, S.-B.; Kim, T.-H.; Pyun, S.-J. J. Org. Chem. 1996, 61, 2604. (m) Kang, S.-K.; Baik, T.-G.; Hur, Y. Tetrahedron 1999, 55, 6863. (n) Kang, S.-K.; Ha, Y.-H.; Yang, H.-Y. J. Chem. Res. (S) 2002, 282. (o) Wang, L.; Chen, Z.-C. Synth. Commun. 2000, 30, 3607. (p) Liang, Y.; Luo, S.; Liu, C.; Wu, X.; Ma, Y. Tetrahedron 2000, 56, 2961. (q) Zhu, M.; Song, Y.; Cao, Y. Synthesis 2007, 853. (r) Radhakrishnan, U.; Stang, P. J. Org. Lett. 2001, 3, 859. (s) Becht, J.-M.; Le Drian, C. Org. Lett. 2008, 10, 3161. (t) Deprez, N. R.; Kalyani, D.; Krause, A.; Sanford, M. S. J. Am. Chem. Soc. 2006, 128, 4972. (u) Canty, A. J.; Patel, J.; Rodemann, T.; Ryan, J. H.; Skelton, B. W.; White, A. H. Organometallics 2004, 23, 3466. (v) Bedford, R. B.; Webster, R. L.; Mitchell, C. J. Org. 
Biomol. Chem. 2009, 7, 4853. (w) Li, W.; Zhang, J. Chem. Commun. 2010, 46, 8839. (x) Tang, S.; Peng, P.; Zhong, P.; Li, J.-H. J. Org. Chem. 2008, 73, 5476. (y) Wagner, A. M.; Sanford, M. S. Org. Lett. 2011, 13, 288. (z) Aydin, J.; Larsson, J. M.; Selander, N.; Szabo, K. J. Org. Lett. 2009, 11, 2852.

38. (a) Kitamura, T.; Yamane, M.; Inoue, K.; Todaka, M.; Fukatsu, N.; Meng, Z.; Fujiwara, Y. J. Am. Chem. Soc. 1999, 121, 11674. (b) Kitamura, T.; Meng, Z.; Fujiwara, Y. Tetrahedron Lett. 2000, 41, 6611. (c) Kitamura, T.; Wasai, K.; Todaka, M.; Fujiwara, Y. Synlett 1999, 731. (d) Kitamura, T.; Aoki, Y.; Isshiki, S.; Wasai, K.; Fujiwara, Y. Tetrahedron Lett. 2006, 47, 1709. (e) Kitamura, T.; Abe, T.; Fujiwara, Y.; Yamaji, T. Synthesis 2003, 213.

39. (a) Xue, J.; Huang, X. Synth. Commun. 2007, 37, 2179. (b) Kamila, S.; Koh, B.; Biehl, E. R. Synth. Commun. 2006, 36, 3493. (c) Thiemann, T.; Fujii, H.; Ohira, D.; Arima, K.; Li, Y.; Mataka, S. New J. Chem. 2003, 27, 1377. (d) Xue, J.; Yang, Y.; Huang, X. Synlett 2007, 1533. (e) Rao, U. N.; Sathunuru, R.; Maguire, J. A.; Biehl, E. J. Heterocycl. Chem. 2004, 41, 13. (f) Chen, Y.-L.; Hau, C.-K.; Wang, H.; He, H.; Wong, M.-S.; Lee, A. W. M. J. Org. Chem. 2006, 71, 3512. (g) Lee, T.; Jeon, J.; Song, K. H.; Jung, I.; Baik, C.; Park, K.-M.; Lee, S. S.; Kang, S. O.; Ko, J. J. Chem. Soc., Dalton Trans. 2004, 933.

40. Allen, A. E.; MacMillan, D. W. C. J. Am. Chem. Soc. 2011, 133, 4260.

41. (a) Okuyama, T.; Fujita, M. Acc. Chem. Res. 2005, 38, 679. (b) Fujita, M.; Kim, W. H.; Sakanishi, Y.; Fujiwara, K.; Hirayama, S.; Okuyama, T.; Ohki, Y.; Tatsumi, K.; Yoshioka, Y. J. Am. Chem. Soc. 2004, 126, 7548. (c) Fujita, M.; Sakanishi, Y.; Nishii, M.; Yamataka, H.; Okuyama, T. J. Org. Chem. 2002, 67, 8130. (d) Fujita, M.; Kim, W. H.; Fujiwara, K.; Okuyama, T. J. Org. Chem. 2005, 70, 480. (e) Hinkle, R. J.; Mikowski, A. M. Arkivoc 2003, vi, 201. (f) Fujita, M.; Sakanishi, Y.; Nishii, M.; Okuyama, T. J. Org. Chem. 2002, 67, 8138. (g) Slegt, M.; Gronheid, R.; Van der Vlugt, D.; Ochiai, M.; Okuyama, T.; Zuilhof, H.; Overkleeft, H. S.; Lodder, G. J. Org. Chem. 2006, 71, 2227. (h) Fujita, M.; Sakanishi, Y.; Kim, W. H.; Okuyama, T. Chem. Lett. 2002, 908. (i) Fujita, M.; Ihara, K.; Kim, W. H.; Okuyama, T. Bull. Chem. Soc. Jpn. 2003, 76, 1849.

42. (a) Yan, J.; Jin, H.; Chen, Z. J. Chem. Res. 2007, 233. (b) Zhang, P.-F.; Chen, Z.-C. J. Chem. Res. (S) 2002, 388.

43. (a) Guan, T.; Yoshida, M.; Hara, S. J. Org. Chem. 2007, 72, 9617. (b) Hara, S.; Guan, T.; Yoshida, M. Org. Lett. 2006, 8, 2639.

44. Ochiai, M.; Shu, T.; Nagaoka, T.; Kitagawa, Y. J. Org. Chem. 1997, 62, 2130.

45. (a) Kang, S.-K.; Yamaguchi, T.; Kim, T.-H.; Ho, P.-S. J. Org. Chem. 1996, 61, 9082. (b) Huang, X.; Xu, X.-H. J. Chem. Soc., Perkin Trans. 1 1998, 3321. (c) Kang, S.-K.; Yoon, S.K.; Kim, Y.-M. Org. Lett. 2001, 3, 2697. (d) Thielges, S.; Bisseret, P.; Eustache, J. Org. Lett. 2005, 7, 681 .

46. (a) Moriarty, R. M.; Epa, W. R.; Awasthi, A. K. J. Am. Chem. Soc. 1991, 113, 6315. (b) Yoshida, M.; Hara, S.; Fukuhara, T.; Yoneda, N. Tetrahedron Lett. 2000, 41, 3887. (c) Yoshida, M.; Yoshikawa, S.; Fukuhara, T.; Yoneda, N.; Hara, S. Tetrahedron 2001, 57, 7143. (d) Yoshida, M.; Komata, A.; Hara, S. J. Fluorine Chem. 2004, 125, 527. 
47. (a) Guan, T.; Takemura, K.; Senboku, H.; Yoshida, M.; Hara, S. Tetrahedron Lett. 2007, 49, 76. (b) Ochiai, M.; Uemura, K.; Masaki, Y. J. Am. Chem. Soc. 1993, 115, 2528. (c) Ochiai, M.; Kunishima, M.; Tani, S.; Nagao, Y. J. Am. Chem. Soc. 1991, 113, 3135.

48. (a) Ochiai, M.; Ito, T.; Takaoka, Y.; Masaki, Y.; Kunishima, M.; Tani, S.; Nagao, Y. J. Chem. Soc., Chem. Commun. 1990, 118. (b) Stang, P. J.; Murch, P. Synthesis 1997, 1378. (c) Zhang, J.-L.; Chen, Z.-C. Synth. Commun. 1997, 27, 3757. (d) Zhang, J.-L.; Chen, Z.-C. Synth. Commun. 1997, 27, 3881. (e) Zhang, J.-L.; Chen, Z.-C. Synth. Commun. 1998, 28, 175. (f) Kitamura, T.; Tashi, N.; Tsuda, K.; Chen, H.; Fujiwara, Y. Heterocycles 2000, 52, 303. (g) Kerwin, S. M.; Nadipuram, A. Synlett 2004, 1404. (h) Witulski, B.; Stengel, T. Angew. Chem., Int. Ed. 1999, 38, 2426. (i) Hashmi, A. S. K.; Salathe, R.; Frey, W. Synlett 2007, 1763. (j) Martinez-Esperon, M. F.; Rodriguez, D.; Castedo, L.; Saa, C. Org. Lett. 2005, 7, 2213. (k) Bykowski, D.; McDonald, R.; Tykwinski, R. R. Arkivoc 2003, vi, 21. (1) Canty, A. J.; Rodemann, T. Inorg. Chem. Commun. 2003, 6, 1382. (m) Canty, A. J.; Watson, R. P.; Karpiniec, S. S.; Rodemann, T.; Gardiner, M. G.; Jones, R. C. Organometallics 2008, 27, 3203.

49. (a) Kitamura, T.; Lee, C. H.; Taniguchi, Y.; Fujiwara, Y.; Matsumoto, M.; Sano, Y. J. Am. Chem. Soc. 1997, 119, 619. (b) Yang, D.-Y.; He, J.; Miao, S. Synth. Commun. 2003, 33, 2695. (c) Yu, C.-M.; Kweon, J.-H.; Ho, P.-S.; Kang, S.-C.; Lee, G. Y. Synlett 2005, 2631.

50. (a) Feldman, K. S. Arkivoc 2003, vi, 179. (b) Feldman, K. S. In Strategies and Tactics in Organic Synthesis; Harmata, M., Ed.; Elsevier: London, 2004; Vol. 4. (c) Liu, Z.; Chen, Z.C.; Zheng, Q.-G. J. Chem. Res. (S) 2003, 715. (d) Liu, Z.; Chen, Z.-C.; Zheng, Q.-G. J. Heteterocycl. Chem. 2003, 40, 909. (e) Liu, Z.; Chen, Z.-C.; Zheng, Q.-G. Synth. Commun. 2004, 34, 361.

51. (a) Miyamoto, K.; Nishi, Y.; Ochiai, M. Angew. Chem. Int. Ed. 2005, 44, 6896. (b) Wipf, P.; Venkatraman, S. J. Org. Chem. 1996, 61, 8004.

52. (a) Montanari, V.; Resnati, G. Tetrahedron Lett. 1994, 35, 8015. (b) DesMarteau, D. D.; Montanari, V. Chem. Lett. 2000, 1052. (c) DesMarteau, D. D.; Montanari, V. J. Fluorine Chem. 2001, 109, 19. (d) Montanari, V.; Kumar, K. J. Fluorine. Chem. 2006, 127, 565. (e) Montanari, V.; Kumar, K. Eur. J. Org. Chem. 2006, 874. (f) Lu, C.; VanDerveer, D.; DesMarteau, D. D. Org. Lett. 2008, 10, 5565.

53. Zhdankin, V. V.; Erickson, S. A.; Hanson, K. J. J. Am. Chem. Soc. 1997, 119, 4775.

54. (a) Zhdankin, V. V.; Tykwinski, R.; Caple, R.; Berglund, B.; Kozmin, A. S.; Zefirov, N. S. Tetrahedron Lett. 1988, 29, 3703. (b) Zhdankin, V. V.; Tykwinski, R.; Mullikin, M.; Berglund, B.; Caple, R.; Zefirov, N. S.; Kozmin, A. S. J. Org. Chem. 1989, 54, 2605.

55. (a) Lee, Y.-S.; Hodoscek, M.; Chun, J.-H.; Pike, V. W. Chem.--Eur. J. 2010, 16, 10418. (b) Chun, J.-H.; Lu, S.; Lee, Y.-S.; Pike, V. W. J. Org. Chem. 2010, 75, 3332. (c) Chun, J.-H.; Lu, S.; Pike, V. W. Eur. J. Org. Chem., No pp yet given. (d) Shah, A.; Pike, V. W.; Widdowson, D. A. J. Chem. Soc., Perkin Trans. 1 1998, 2043. (e) Zhang, M.-R.; Kumata, K.; Suzuki, K. Tetrahedron Lett. 2007, 48, 8632. (f) Ross, T. L.; Ermert, J.; Hocke, C.; Coenen, H. H. J. Am. Chem. Soc. 2007, 129, 8018. (g) Graskemper, J. W.; Wang, B.; Qin, L.; 
Neumann, K. D.; DiMagno, S. G. Org. Lett. 2011, 13, 3158. (h) Wang, B.; Graskemper, J. W.; Qin, L.; DiMagno, S. G. Angew. Chem., Int. Ed. 2010, 49, 4079. (i) Carroll, M. A.; Jones, C.; Tang, S.-L. J. Labelled Compd. Radiopharm. 2007, 50, 450. (j) Carroll, M. A.; Nairne, J.; Woodcraft, J. L. J. Labelled Compd. Radiopharm. 2007, 50, 452. (k) Carroll, M. A.; Nairne, J.; Smith, G.; Widdowson, D. A. J. Fluorine. Chem. 2007, 128, 127. (1) Ermert, J.; Hocke, C.; Ludwig, T.; Gail, R.; Coenen, H. H. J. Labelled Compd. Radiopharm. 2004, 47, 429. (m) Wuest, F. R.; Kniess, T. J. Labelled Compd. Radiopharm. 2003, 46, 699.

\section{Authors Biographies}

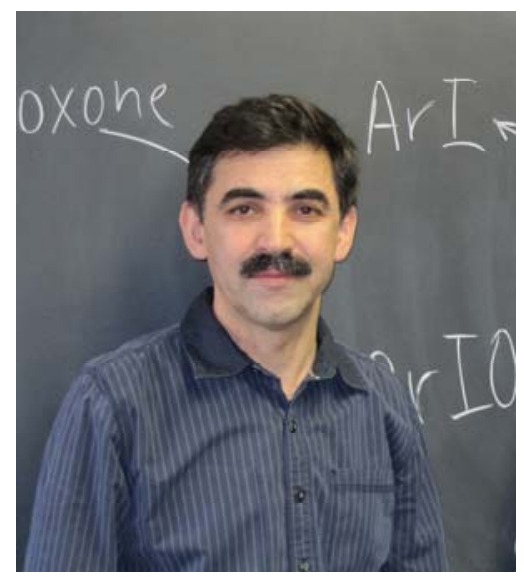

Mekhman S. Yusubov: born in Georgia. His M.S. (1985), Ph.D. (1991), and Doctor of Chemical Sciences (1998) degrees were earned at Tomsk Polytechnic University in the laboratory of Professor Victor D. Filimonov. He is a Head of Chemistry Department at Siberian State Medical University and a Professor of Tomsk Polytechnic University. Since 1994 he has been involved in intense international collaborative research programs with leading research laboratories in South Korea, Germany and United Kingdom. In 2004 he started a joint research in the area of hypervalent iodine chemistry with Professor V. V. Zhdankin in University of Minnesota Duluth. His main research interests are in the fields of chemistry of natural products and hypervalent iodine reagents. Professor M. S. Yusubov has published over 100 scientific papers. 


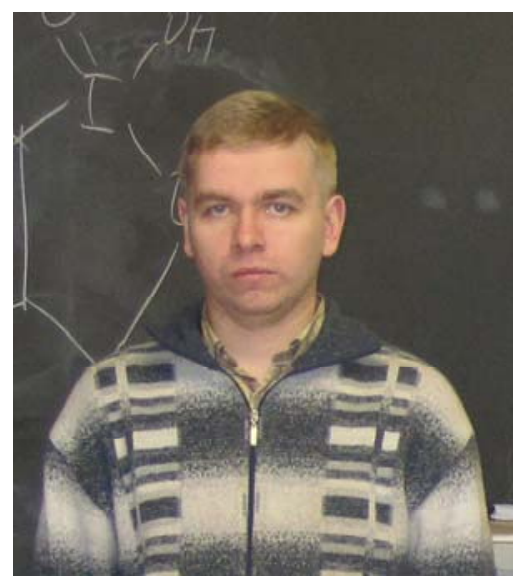

Andrey V. Maskaev: was born in Saratov, Russian Federation. In 2005 he graduated from Higher Chemical College of the Russian Academy of Sciences (Moscow, Russia) with MS degree in Organic Chemistry. After graduation he was employed as a synthetic and research chemist at ASINEX (2005-2008) and as a chemistry consultant in a patent company (20082009). In 2010 he joined the research group of Professor Viktor V. Zhdankin at the University of Minnesota Duluth. His current research is focused on the development of new hypervalent iodine reagents as useful synthetic tools for organic and medicinal chemistry.

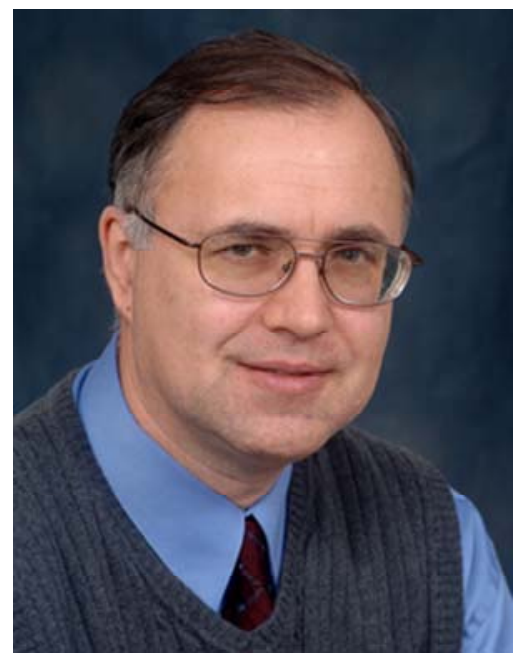

Viktor V. Zhdankin: was born in Ekaterinburg, Russian Federation. His M.S. (1978), Ph.D. (1981), and Doctor of Chemical Sciences (1986) degrees were earned at Moscow State University in the research laboratories of Professor Nikolay S. Zefirov. He moved to the University of Utah in 1990, where he worked for three years as Instructor of organic chemistry and Research Associate with Professor Peter J. Stang. In 1993, he joined the faculty of the University of Minnesota Duluth, where he is currently a Professor of Chemistry. He published over 220 scientific papers, edited several books, and co-authored the Handbook of Heterocyclic Chemistry (3rd Edition, 2010) with Professors A. R. Katritzky, C. A. Ramsden, and J. A. Joule. His main research interests are in the fields of synthetic and mechanistic organic chemistry of hypervalent main-group elements (iodine, xenon, selenium, sulfur, and phosphorus) and 
organofluorine chemistry. In 2011 he was a recipient of National Award of the American Chemical Society for Creative Research \& Applications of Iodine Chemistry. Since 2003 he is Scientific Editor and a Member of Control Board of Arkivoc. 